\title{
A New Time-of-Flight Aerosol Mass Spectrometer (TOF-AMS)_Instrument Description and First Field Deployment
}

\author{
Frank Drewnick, ${ }^{1}$ Silke S. Hings, ${ }^{1}$ Peter DeCarlo, ${ }^{2,3}$ John T. Jayne, ${ }^{5}$ Marc Gonin, ${ }^{6}$ \\ Katrin Fuhrer, ${ }^{6}$ Silke Weimer, ${ }^{7,8}$ Jose L. Jimenez, ${ }^{3,4}$ Kenneth L. Demerjian, ${ }^{7}$ \\ Stephan Borrmann, ${ }^{1,9}$ and Douglas R. Worsnop ${ }^{5}$ \\ ${ }^{1}$ Max Planck Institute for Chemistry, Cloud Physics and Chemistry Department, Mainz, Germany \\ ${ }^{2}$ Program in Atmospheric and Oceanic Sciences, University of Colorado, Boulder, Colorado, USA \\ ${ }^{3}$ CIRES, University of Colorado, Boulder, Colorado, USA \\ ${ }^{4}$ Department of Chemistry \& Biochemistry, Boulder, Colorado, USA \\ ${ }^{5}$ Aerodyne Research, Inc., Billerica, Massachusetts, USA \\ ${ }^{6}$ TOFWERK AG, Thun, Switzerland \\ ${ }^{7}$ State University of New York, Atmospheric Sciences Research Center, Albany, New York, USA \\ ${ }^{8}$ Now at: EMPA, Dübendorf, Switzerland, and Paul Scherrer Institute, Villigen, Switzerland \\ ${ }^{9}$ Institute for Atmospheric Physics, University of Mainz, Mainz, Germany
}

We report the development and first field deployment of a new version of the Aerosol Mass Spectrometer (AMS), which is capable of measuring non-refractory aerosol mass concentrations, chemically speciated mass distributions and single particle information. The instrument was constructed by interfacing the well-characterized Aerodyne AMS vacuum system, particle focusing, sizing, and evaporation/ionization components, with a compact TOFWERK orthogonal acceleration reflectron time-of-flight mass spectrometer. In this time-of-flight aerosol mass spectrometer (TOF-AMS) aerosol particles are focused by an aerodynamic lens assembly as a narrow beam into the vacuum chamber. Non-

Received 30 December 2004; accepted 13 May 2005.

The PMTACS-NY 2004 deployment of the TOF-AMS was supported in part by the New York State Energy Research and Development Authority (NYSERDA), contract \#4918ERTERE-S99 and the U.S. Environmental Protection Agency (EPA), contract \#R828060010. Although the research described in this article has been funded in part by the U.S. EPA, it has not been subjected to the Agency's peer and policy review and therefore does not necessarily reflect the views of the Agency, and no official endorsement should be inferred. We thank Phil Mortimer from Aerodyne Research, Inc., James Schwab from ASRC at SUNY Albany, and Queens College for logistical support during the PMTACS campaign. S. Hings thanks International Max Planck Research School for funding for her participation in this work. J.L. Jimenez and P. DeCarlo thank the U.S. Dept. of Energy (DE-FG02-03ER83599) and the Office of Naval Research (grant N00244-04-P-0425) for funding participation in this work.

Address correspondence to Frank Drewnick, Max Planck Institute for Chemistry, Cloud Physics and Chemistry Department, J. J. Becherweg 27, D-55128 Mainz, Germany. E-mail: drewnick@ mpch-mainz.mpg.de refractory particle components flash-vaporize after impaction onto the vaporizer and are ionized by electron impact. The ions are continuously guided into the source region of the time-of-flight mass spectrometer, where ions are extracted into the TOF section at a repetition rate of $83.3 \mathrm{kHz}$. Each extraction generates a complete mass spectrum, which is processed by a fast (sampling rate $1 \mathrm{Gs} / \mathrm{s}$ ) data acquisition board and a PC. Particle size information is obtained by chopping the particle beam followed by time-resolved detection of the particle evaporation events. Due to the capability of the time-of-flight mass spectrometer of measuring complete mass spectra for every extraction, complete single particle mass spectra can be collected. This mode provides quantitative information on single particle composition. The TOF-AMS allows a direct measurement of internal and external mixture of non-refractory particle components as well as sensitive ensemble average particle composition and chemically resolved size distribution measurements. Here we describe for the first time the TOF-AMS and its operation as well as results from its first field deployment during the $\mathbf{P M}_{2.5}$ Technology Assessment and Characterization Study-New York (PMTACS-NY) Winter Intensive in January 2004 in Queens, New York. These results show the capability of the TOF-AMS to measure quantitative aerosol composition and chemically resolved size distributions of the ambient aerosol. In addition it is shown that the single particle information collected with the instrument gives direct information about internal and external mixture of particle components.

\section{INTRODUCTION}

Aerosol particles participate in many physical and chemical processes in the atmosphere such as climate forcing through direct and indirect effects, heterogeneous chemistry, or visibility reduction (Andreae et al. 1997; Seinfeld and Pandis 1998; IPCC 
2001; Warneck 1999; Watson 2002). In addition due to their impact on human health, aerosols are increasingly recognized as a major concern in urban air quality (Pope et al. 2002; Samet et al. 2000; Wichmann et al. 2000). However, many questions about particle formation, transport, transformation and impact remain largely unanswered, in good part due to limitations of available instrumentation.

In the last decade intensive research and development has resulted in significant improvements in aerosol measurement capabilities and a wealth of new fast and sensitive aerosol measurement instruments. Among these, aerosol mass spectrometry has proved to be a versatile and highly sensitive method for aerosol analysis (McMurry 2000; Johnston 2000).

A milestone in the development of aerosol mass spectrometry has been the demonstration and development of online laser vaporization/ionization aerosol mass spectrometers (McKeown et al. 1991; Gard et al. 1997; Murphy and Thomson 1997; Carson et al. 1997a,b). These instruments provide rapid information on the size and chemical composition of single aerosol particles. However, due to the single-step vaporization/ionization process these instruments suffer from biases in the particle-size and chemical composition representation (Reilly et al. 2000; Gross et al. 2000; Allen et al. 2000; Kane and Johnston 2000), limiting their ability of providing quantitative analysis. In addition the optical detection techniques used to trigger the ablation/ionization laser limit the analysis of particles to particle sizes larger than $0.2 \mu \mathrm{m}$ in most of these instruments. Operation of single-step laser ablation instruments with very high laser power fluences has been shown to quantitatively convert particles into atomic ions, leading to quantitative atomic composition analysis (Reents and Ge 2000; Mahadevan et al. 2002). However, it has recently been shown that this approach does not work for all particle compositions (Wang et al. 2004), and in any case only elemental, not molecular information is obtained.

In recent years a number of aerosol mass spectrometers were developed that allow quantitative analysis of aerosol composition by separating the particle evaporation and ionization processes. In some of these instruments particles were evaporated with an intense infrared laser pulse and subsequently ionized by a second UV laser pulse (Zelenyuk et al. 1999; Morrical et al. 1998). Other instruments evaporate collected particles by heating the collection substrate, followed by electron impact or chemical ionization (Tobias and Ziemann 1999; Smith et al. 2004). The Aerosol Mass Spectrometer (AMS) developed by Aerodyne Research, Inc., flash-vaporizes particles, focused by means of an aerodynamic lens system onto a vaporizer and analyses the evolving vapors by electron impact ionization and quadrupole mass spectrometry (Jayne et al. 2000; Jimenez et al. 2003a).

The AMS has been shown in multiple field and laboratory experiments to have the potential for quantitatively measuring chemical composition as well as chemically resolved size distributions (e.g., Drewnick et al. 2003; Schneider et al. 2004; Jimenez et al. 2003a; Hogrefe et al. 2004; Allan et al. 2004;
Zhang et al. 2004a). In order to further improve sensitivity and time resolution of the AMS and to extend its capabilities to determine single particle information the Time-of-Flight Aerosol Mass Spectrometer (TOF-AMS) was developed. This instrument combines the demonstrated features of the AMS particle collection, sizing, and evaporation/ionization technology with state-of-the-art, time-of-flight mass spectrometry. Here we report for the first time on the operation of the TOF-AMS and present results from its first field deployment during the PMTACS-NY 2004 campaign in Queens, New York. A systematic characterization study of the TOF-AMS and its capabilities is currently in progress and will be the subject of a forthcoming publication.

The $\mathrm{PM}_{2.5}$ Technology Assessment and Characterization Study - New York (PMTACS-NY) was one of several US EPA "Supersites," intended to provide enhanced measurement data on chemical and physical properties of particulate matter and its associated precursors. One of the primary objectives of this study is to test and evaluate recently developed aerosol measurement technologies like the TOF-AMS. The PMTACS-NY 2004 study was a winter study, performed at the same location as the PMTACS-NY 2001 summer campaign (e.g., Drewnick et al. 2004a,b) on the campus of Queens College in Queens, New York.

\section{INSTRUMENT DESCRIPTION}

The Time-of-Flight Aerosol Mass Spectrometer (TOF-AMS) is a combination of the well-characterized quadrupole mass spectrometer-based Aerodyne AMS (from here on called "QAMS") aerosol sampling, sizing and evaporation/ionization technology (e.g., Jayne et al. 2000; Jimenez et al. 2003a) and a compact TOFWERK orthogonal extraction time-of-flight mass spectrometer (TOF-MS, e.g., Steiner et al. 2001). An instrument schematic of the TOF-AMS is given in Figure 1.

The TOF-AMS in its current version is mounted in a single mobile rack with the vacuum system, the mass spectrometer and the whole electronics, including data acquisition system integrated. The rack dimensions are $104 \times 61 \times 124 \mathrm{~cm}$ (rack volume $\sim 0.79 \mathrm{~m}^{3}$ ) and the TOF-AMS weighs about $200 \mathrm{~kg}$. Under sampling conditions the instrument has a power consumption of approximately $600 \mathrm{~W}$ with about $1 / 3$ of this power being used by the data acquisition computer and the instrument electronics, the remaining being consumed by the vacuum system (5 turbo pumps and the single backing pump). During the PMTACS-NY campaign the instrument was operated in a preliminary set-up with the vacuum system and the mass spectrometer separated from the electronics rack.

Here we describe the components of the TOF-AMS that are different from those in the Q-AMS, and their most important characteristics. Further information is given in Jayne et al. (2000) about the AMS chamber and in Steiner et al. (2001) about the time-of-flight mass spectrometer.

The TOF-AMS vacuum system consists of five individual, differentially pumped chambers: the aerosol sampling chamber, 


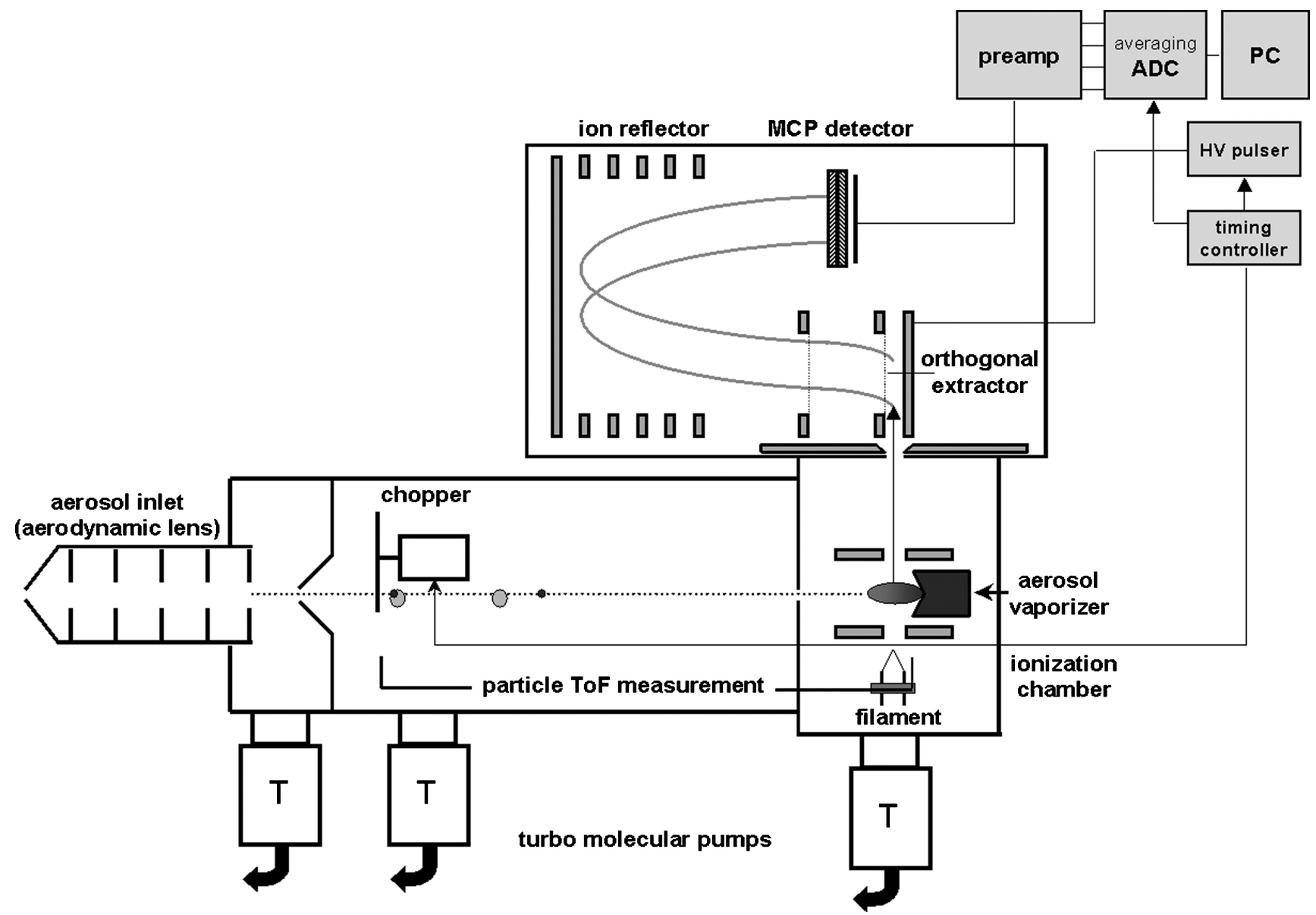

FIG. 1. Schematic of the Time-of-Flight Aerosol Mass Spectrometer (TOF-AMS). Aerosol is introduced into the instrument through an aerodynamic lens focusing the particles through a skimmer and an orifice onto the vaporizer. Particle vapor is ionized and the ions are guided into the TOF-MS, which generates mass spectra at $\sim 83.3 \mathrm{kHz}$ repetition rate. For particle size measurement the particle beam is chopped with a mechanical chopper and the detection is synchronized with the chopper opening time.

the particle-sizing chamber, the particle evaporation and ionization chamber (two chambers), and the TOF-MS chamber. The aerosol is sampled at a flow rate of approximately $1.4 \mathrm{~cm}^{3} / \mathrm{s}$ into the aerosol-sampling chamber through a critical orifice of $100 \mu \mathrm{m}$ ID and an aerodynamic lens system (Zhang et al. $2002,2004 \mathrm{~b}$ ) that focuses particles in the size range $\sim 50 \mathrm{~nm}$ to $\sim 600 \mathrm{~nm}$ into a narrow beam.

Behind the critical orifice the pressure drops to about $1.8 \mathrm{hPa}$, depending on the mass flow rate into the inlet. This pressure is monitored with a sensitive capacitance pressure gauge (MKS Baratron, 0-10 Torr $(0-13.33 \mathrm{hPa}))$, which provides a continuous inlet flow rate measurement via external calibration with a bubble flow meter. The lens focuses particles in the above mentioned size range with almost $100 \%$ efficiency into a narrow beam of $\sim 100 \mu \mathrm{m}$ diameter a few $\mathrm{cm}$ behind the lens exit (Heberlein et al. 2001). Smaller and larger particles are also transmitted albeit with reduced efficiency.

The particle beam leaves the aerosol-sampling chamber through a $1 \mathrm{~mm}$ ID channel skimmer, which skims off most of the air entering the inlet while transmitting the particle beam into the particle-sizing chamber. The air is removed from the aerosol-sampling chamber by a $280 \mathrm{l} / \mathrm{s}$ turbo molecular pump (Varian V-301 NAV), backed by a diaphragm pump (Vacuubrand MD1-Vario). The particle-sizing chamber is pumped by a $70 \mathrm{l} / \mathrm{s}$ turbo molecular pump (Varian V-70LP). This pump as well as the other downstream turbo pumps is backed by the inlet turbo molecular pump so that only a single roughing pump is needed for the whole system.

In the expansion of the air into the vacuum chamber at the final nozzle of the aerodynamic lens the particles are accelerated to a terminal velocity that depends on their aerodynamic size (see next section), which is retained in the vacuum chamber due to the lack of horizontal forces acting on the particles under the high vacuum conditions. This effect is used to determine particle size by measuring particle velocity in the particlesizing chamber. For this purpose a mechanical chopper wheel is mounted at the front end of this chamber with two radial slits, each cutting through $0.5 \%$ of the chopper circumference, so that the effective opening duty cycle is $1 \%$. Particle size information is obtained by chopping the particle beam and collecting 
complete mass spectra as a function of particle time-of-flight with the mass spectrometer synchronized with the chopper rotation. The recording of complete mass spectra at each time step in a chopper cycle is a major difference with the Q-AMS, in which only one $m / z$ is scanned for a given chopper cycle. This improvement in measurement duty cycle results in a large improvement in particle sampling statistics with respect to the Q-AMS, as discussed below. Complete non-refractory particle composition information (all $\mathrm{m} / \mathrm{z}$ 's) without any sizing is collected with the chopper completely removed from the particle beam in order to maximize particle transmission, and alternatively blocking the whole beam in order to record the background signals for subtraction. Again in this MS mode of the TOF-AMS a complete mass spectrum is acquired every $12 \mu \mathrm{s}$, while in the Q-AMS the mass spectrum is scanned over a mass range of $m / z 1-300$ within $300 \mathrm{~ms}$, with only one $m / z$ being detected at a given time. Again this higher duty cycle results in greatly improved particle sampling statistics with respect to the Q-AMS.

After traveling through the particle-sizing chamber, the particles enter the particle evaporation and ionization chamber through a $3.8 \mathrm{~mm}$ orifice. This chamber consists of an outer volume which is pumped by a $70 \mathrm{l} / \mathrm{s}$ turbo molecular pump (Varian V-70LP), and the inner chamber which is pumped to a pressure of approximately $2 \times 10^{-5} \mathrm{~Pa}$ by a $280 \mathrm{l} / \mathrm{s}$ turbo molecular pump (Varian V-301 NAV). The particles impact onto the vaporizer, located at the downstream end inside a compact cross beam electron impact ion source. The particle vaporizer (as well as the entire ionizer) used on the TOF-AMS is identical to that used on the Q-AMS systems. The vaporizer has a diameter of $3.8 \mathrm{~mm}$ and is custom-built from porous tungsten, $\sim 20 \%$ void volume with pore sizes of $\sim 100-200 \mu \mathrm{m}$. The front section of the vaporizer where the particles impact has an inverted cone shape, a 60-degree included angle. Both the cone shape and the porosity are to enhance capture from bouncing particles. The vaporizer is brazed onto a molybdenum heater body (containing an embedded resistive wire potted in ceramic) and is therefore heated by conduction. The vaporizer temperature is measured with a micro thermocouple that is fixed on the front OD of the vaporizer and can be adjusted in a range from about $250^{\circ} \mathrm{C}$ (limited by radiative heating from the electron emission filament) up to $\sim 1000^{\circ} \mathrm{C}$. Typical operating power of $2 \mathrm{~W}$ provides $\sim 600^{\circ} \mathrm{C}$ near the vaporizer surface.

A key to this design (identical to the Q-AMS system) is mounting the vaporizer in the center of the ionizer such that essentially every molecule that leaves the vaporizer passes through the ionization volume that is imaged into the mass spectrometer. It is necessary to apply a voltage bias to the vaporizer to "retune" the distorted electric field caused by placing the vaporizer inside the ionizer. This voltage is typically within several volts of the ion reference voltage. The ionizer used in the TOF-AMS is a commercial cross-beam ionizer (Inficon/Balzers) with reduced volume, compared to the standard cross-beam ionizer. The nonrefractory aerosol components flash-evaporate quickly (within $50-100 \mu \mathrm{s})$ after impaction of the particles on the vaporizer. The resulting vapor molecules are ionized by $70 \mathrm{eV}$ electrons emitted from a tungsten filament located to the side of the ion source. Ions are extracted from the ion source via a lens at a potential of about $-100 \mathrm{~V}$ and focused into a beam with an Einzel lens, decelerated to about $50 \mathrm{eV}$. Instead of being directly injected into the Q-AMS, in the TOF-AMS ions are transferred $96 \mathrm{~mm}$ to the orthogonal TOF extractor through electrostatic lenses, which are designed to keep the ion loss as small as possible. The electrostatic focusing should also keep mass discrimination effects at minimum as in electrostatic fields the trajectories of particles with equal $E / q$ are identical. This means that those components of the initial ion velocities which have a mass dependence (essentially the plume velocity) become negligible compared to the $100 \mathrm{eV}$ extraction energy. The main contribution of the initial ion energy variability stems from the position of ionization in the relatively strong extraction field within the ionizer, which should not be mass dependent.

The ions enter the TOF-MS through a hole of approximately $6 \mathrm{~mm}$ diameter. The TOF-MS is housed in a compact vacuum chamber of $265 \times 155 \times 75 \mathrm{~mm}$, pumped by another $701 / \mathrm{s}$ turbo molecular pump (Varian V-70LP). The ions are guided and collimated into the ion extractor. The open area of the extractor is 46-mm long and matches the active area of the MCP detector. The ions drift through the TOF extractor at $50 \mathrm{eV}$ before they are orthogonally extracted into the TOF section by a pulsed high voltage. After each extraction pulse the ions have to refill the extractor. This "fill up time" is $m / z$ dependent and determines the $m / z$ dependent ion duty cycle. Lighter ions have a short fill up time after which the extractor is "overfilled" and ions are lost. This leads to a lower duty cycle compared to heavier ions whose fill up time is comparable to the TOF extraction period. Hence, the TOF-MS ion duty cycle increases with square root of mass and reaches about $30 \%$ for the largest ion, which's TOF just matches the extraction period. Typically the extraction period is $12 \mu$ s, generating 83,300 complete mass spectra per second. The ion drift energy is roughly $2 \mathrm{kV}$. The TOF-MS is equipped with a two-stage gridded ion reflector, resulting in an effective flight path of $430 \mathrm{~mm}$. After post acceleration the ions are collected by a $40 \mathrm{~mm}$ chevron stack MCP detector (modified MCP 40/12/8 D EDR 46:1 CZ TC set, Burle Technologies, Inc., Sturbridge, MA). All voltages of the TOF-MS, the ionizer, and the filament current are generated using a custom-built power supply. The time-of-flight mass spectrometer is described in more detail in Steiner et al. (2001). The MCP output signal is detected in two channels of a high-speed (1 Gs/s) analog-to-digital conversion data acquisition card (AP240, Acqiris, Geneva, Switzerland) in parallel. One channel records the mass spectral signal with an amplification of 11 (Amplifier Model ACA-2-21-N, Becker \& Hickel $\mathrm{GmbH}$, Germany), and the other without any amplification, for extension of the dynamic range. Data collected by the data acquisition card are transferred to a personal computer and stored to disc. For high-duty cycle spectrum acquisition raw mass spectra collected on the ADC card are averaged on the card in real time before transfer to the PC every few seconds. 


\section{INSTRUMENT OPERATION DURING PMTACS-NY}

The TOF-AMS records data in three different modes of operation: The MS (Mass Spectrum) mode, the P-TOF (Particle Time-of-Flight) mode, and the SP-TOF (Single Particle Timeof-Flight) mode. The data acquisition software currently under development will allow the instrument to shift back and forth between the different operation modes every few seconds. However, the instrument was used with a first version of the data acquisition software during the PMTACS-NY 2004 campaign, which did not allow the rapid programmable alternation of all three operating modes.

The MS or (averaged) Mass Spectrum mode is used to collect averaged mass spectra of the non-refractory aerosol components for an ensemble of particles. In order to maximize the duty cycle in this mode the particle beam chopper is completely moved out of the beam, enabling a maximum number of the particles that are entering the instrument to impact on the vaporizer, and then closed to allow the recording of background mass spectra. The vapors evolving from the particles are continuously ionized by $70 \mathrm{eV}$ electron impact and the positive ions formed are continuously transferred into the extractor of the TOF-MS.

During PMTACS-NY the orthogonal extraction voltage was pulsed at $83.3 \mathrm{kHz}$, generating a complete mass spectrum every $12 \mu \mathrm{s}$. To keep up with this enormous data stream the mass spectra were averaged in the memory of the data acquisition board in real time. 312,000 spectra were averaged within $3.7 \mathrm{~s}$. Then the particle beam chopper was moved into the beam to completely block it. Now the gas phase background spectrum was measured for another 312,000 spectra or $3.7 \mathrm{~s}$. Every $3.7 \mathrm{~s}$ the averaged mass spectra were transferred to the PC RAM memory under software control. The spectra were further processed and averaged and were saved to a file on the computer hard drive every five min. The average aerosol and gas-phase "difference" spectrum was calculated from the average mass spectrum with the particle beam not blocked by the chopper ("beam open" spectrum) minus the average background mass spectrum ("beam closed" spectrum). From these high-resolution mass spectra, where the MCP signal was recorded with 1 ns time resolution, unit mass resolution spectra (one signal intensity per $\mathrm{m} / \mathrm{z}$ ) were also calculated. They were calculated from the raw mass spectra by integration of the signal area at every $m / z$, which is proportional to the ion current. The $m / z$ ranges of interest were defined by an $m / z$ calibration, performed before each start of the data acquisition. This ion mass calibration uses the flight times and known $m / z$ 's of two easy-to-identify background peaks. From this information a calibration curve, relating ion TOF vs. $m / z$ is calculated for the whole mass spectrum ranging from $m / z 4$ to 206 during the NYC campaign. In Figure 2, the raw (beam open, beam closed and difference spectrum) and unit-resolution (difference) mass spectra are shown for one 5-min averaging interval. The signal intensity is given in ions per spectrum. Since the unit-resolution spectrum is the integral over the peak, the number of ions per spectrum for each $m / z$ is higher than the maximum number of ions per spectrum for each individual channel of the high-resolution peak. Note, that signals at $m / z$ that are associated with organic species are much lower than at those associated with inorganic species even though organics represents approximately $50 \%$ of the total non-refractory aerosol mass (see Figure 5 ). This is due to the fact that fragments of organic species are found at a very large number of $m / z$, while the inorganic species fragment only in a small number of major ions.

The P-TOF or (averaged) Particle Time-of-Flight mode is used to collect averaged size distribution data for all nonrefractory aerosol components for an ensemble of particles. In this mode the particle beam is chopped with the mechanical chopper wheel at about $125 \mathrm{~Hz}$. The chopper transmits particles for $1 \%$ of the time $(\sim 80 \mu \mathrm{s})$ and blocks them for the rest of the time $(\sim 7.92 \mathrm{~ms})$. The open or closed position of the chopper is monitored with an LED whose reflection on the chopper is measured by a photodiode, defining the opening time of the chopper when particles are entering the particle sizing chamber at the chopper position. The arrival times of the particles at the vaporizer are determined by time-resolved detection of the mass spectra for each chopper cycle. This is possible since the time scale for evaporation, ionization and mass spectrometric analysis is short ( $\sim 50 \mu \mathrm{s})$ compared to the flight time of the particles through the particle-sizing chamber $(\sim 3 \mathrm{~ms})$.

During the expansion of the air into the vacuum the particles are accelerated to a velocity that depends on the inertia and aerodynamic drag properties of the particles: the smaller and less massive the particles are, the better they can follow the gas molecules in the expansion and the faster their terminal velocity. To a first approximation for spheres the accelerating force during the expansion (approximated by Stokes' drag force) is proportional to $d_{p}^{2}$ and the particle mass is proportional to $d_{p}^{3}$, the acceleration of the particles is proportional to $d_{p}^{-1}$ resulting in a particle velocity proportional to $d_{p}^{-1 / 2}$. The resulting equivalent diameter is known as the vacuum aerodynamic diameter $\left(d_{v a}\right)$ (Jimenez et al. 2003b; DeCarlo et al. 2004). The particle velocity to $d_{v a}$ dependency was determined in the field using monodisperse ammonium nitrate particles of known mobility diameters $\left(d_{m}=50-500 \mathrm{~nm}\right)$, generated with a Collison nebulizer, diffusion dried, and size-selected with a DMA. The DMA was calibrated with polystyrene latex spheres (PSLs, Duke Scientific, Palo Alto, CA). This particle time-of-flight calibration enables the transformation of particle flight times measured for ambient particles into $d_{v a}$ as described in the following section.

At $125 \mathrm{~Hz}$ chopping frequency each chopper cycle (chopper opening and particle time-of-flight measurement cycle) is $8 \mathrm{~ms}$ long. The TOF mass spectrometer was pulsed continuously at $83.3 \mathrm{kHz}$, producing a mass spectrum every $12 \mu \mathrm{s}$. To save data acquisition on-board memory, during the first $100 \mu \mathrm{s}$ of each chopper cycle no data were collected from the mass spectrometer ("data delay"), since no particles or gases can fly down the chamber at the speeds needed to arrive during that delay. After the data delay 520 mass spectra were recorded (spaced by $12 \mu \mathrm{s}$ ) in every chopper cycle, covering $6.24 \mathrm{~ms}$ of the cycle. Due to the limited on-board memory always two consecutive mass 


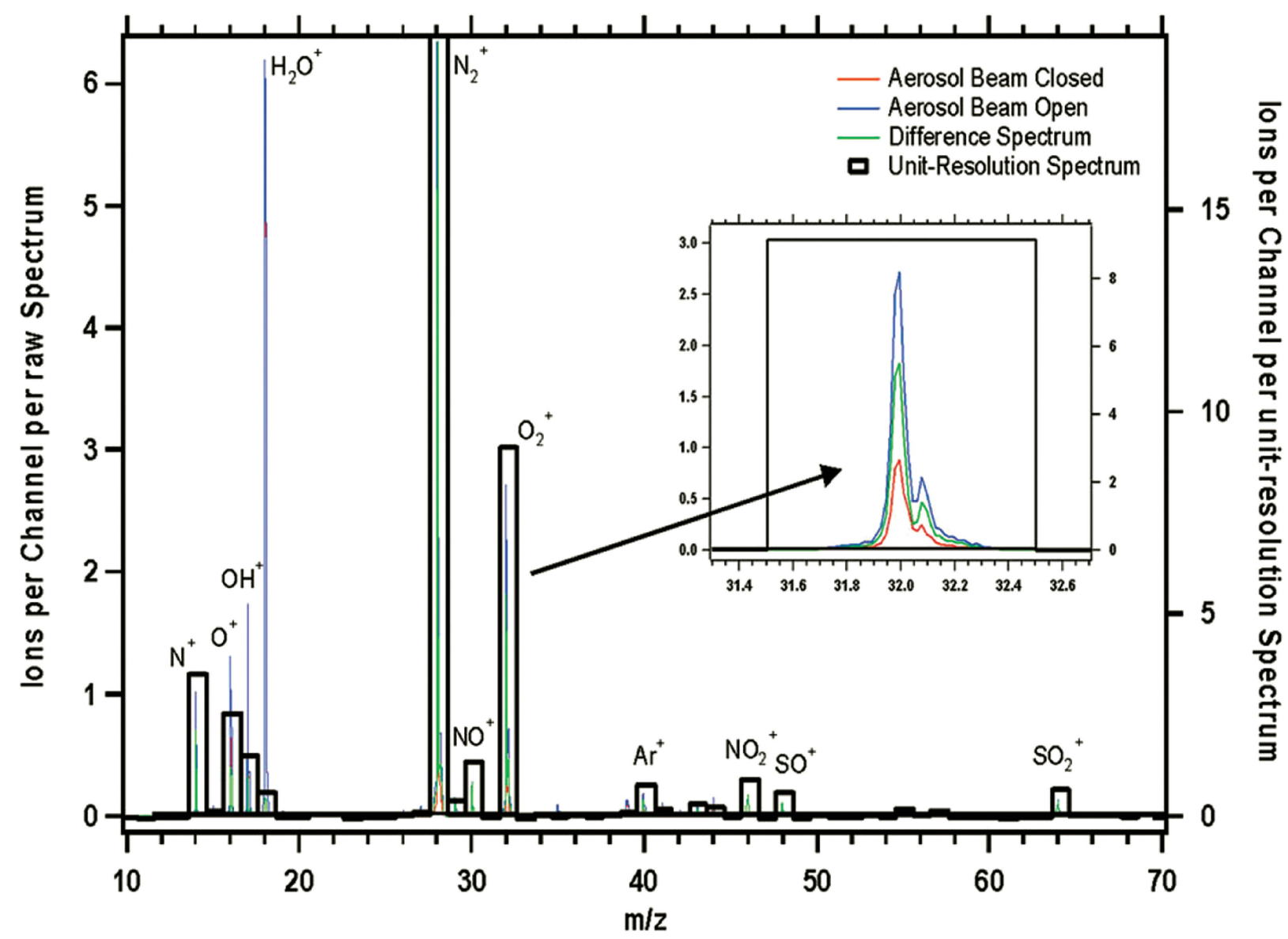

FIG. 2. Raw and unit-resolution mass spectra for one 5-minute average. The unit-resolution mass spectrum is calculated from the difference spectrum (beam open minus beam closed) by integration of the peak areas. Left axis for high-resolution spectra, right axis for unit-resolution spectrum.

spectra were co-added into a separate segment of the memory on the data acquisition card, so that the effective time resolution was $24 \mu \mathrm{s}$. The spectra of every point in the P-TOF cycle (i.e., of every segment of the DAQ-card memory) were individually averaged on the data acquisition card for 600 chopper cycles (using the "round-robin" averaging feature of the Acqiris AP240 board) before transfer into the PC. This results in a matrix of 260 mass spectra, corresponding to 260 P-TOF bins (i.e, $d_{v a}$ bins), each containing the average mass spectrum $(m / z 4-206)$ for a small P-TOF range. Alternatively this matrix can be interpreted as the P-TOF (i.e., size) distribution of each $m / z$ with $24 \mu$ s resolution. Further averaging of these spectra was done in the PC before saving data to a file on the hard drive every five minutes.

The SP-TOF or Single Particle-Time-of-Flight mode is used to collect size-dependent single particle information. In this mode the particle beam is chopped with the mechanical chopper as in the P-TOF mode and the mass spectra are recorded together with the P-TOF information synchronized to the chopper opening. After the $100 \mu$ s data delay 520 mass spectra are recorded with always two adjacent spectra co-added into 260 mass spectra in 260 sections of the DAQ-card. However, no "round-robin" averaging of mass spectra over a large number of chopper cycles is performed in this mode, but the spectra of a single chopper cycle are transferred to the PC and saved to the hard drive directly after the end of the chopper cycle. During PMTACS-2004 the data were transmitted at the raw resolution of $1 \mathrm{~ns}$, which resulted in very large data arrays. Thus this process took significantly longer than the acquisition of the data. For every chopper cycle, which was recorded, 19 cycles were missed during the data transfer and saving time. Nevertheless this mode generated mass spectra of approximately 6 complete chopper cycles (size distributions) per second, which is about 700 kilobyte of unit-resolution spectra per second. The data acquisition software now being programmed will greatly increase the duty cycle by compressing the spectra to unit $m / z$ resolution by the FPGA processor of the DAQ card before transmission to the PC.

During PMTACS-NY 2004 the TOF-AMS was used for continuous aerosol measurements for the first time and a first version of data acquisition software was written just before the campaign and improved during the campaign. This resulted in a significant evolution of the operation of the instrument during the campaign. During the first few days of measurement the instrument was operating only in the MS mode. During most of the campaign the 
instrument was controlled and the data were collected by a first version of a custom data acquisition program that controlled the movement of the chopper, the operation of the data acquisition board, the data transfer to the memory, the processing of the raw data, and the saving of the processed data to disk. For integration of the peaks and calculation of the unit resolution spectra an $\mathrm{m} / \mathrm{z}$ calibration was performed before each start of the data acquisition program using two of the most prominent $\mathrm{m} / \mathrm{z}$ signals in the spectra. The averaging cycles typically contained $5 \mathrm{~min}$ of data alternating several cycles in the P-TOF and MS modes of operation (known as the "alternate" mode). Several times during the campaign the instrument was set to collect data in the SP-TOF mode for a few minutes. However, since the simple SPTOF mode used in this study produced enormous amounts of data, most of the time only averaged P-TOF and MS mode data were collected.

The voltages of the ionizer and the TOF-MS were set manually in a separate control program developed by TOFWERK that communicated with the TOF Power Supply (TPS) via a serial port. The TOF-MS was operated with a drift voltage of $2 \mathrm{kV}$. The filament current was set to $3.5 \mathrm{~A}$, which produced an electron emission current of approximately $2 \mathrm{~mA}$. The ion extractor was pulsed with $83.3 \mathrm{kHz}$ (repetition rate: $12 \mu \mathrm{s}$ ) and the particle beam chopper chopped the beam with approximately $125 \mathrm{~Hz}$.

During the campaign a total of about $50 \mathrm{~h}(\sim 2.1$ days $)$ of only P-TOF mode data were collected, producing almost 7 gigabytes (GB) of data. More than 112 hours ( $4.7 \mathrm{~d}$ ) of only MS mode data resulted in $0.16 \mathrm{~GB}$ of data. In addition the alternate mode (P-TOF and MS modes in rapid alternation) was run for more than 65 hours $(2.7 \mathrm{~d})$, generating $6.6 \mathrm{~GB}$. Single particle data (SP-TOF mode) were collected for 23,143 chopper cycles during 63 min of data collection, spread over five days of the campaign. These data represent a total measuring time of about $190 \mathrm{~s}$, resulting in $2.41 \mathrm{~GB}$ of spectra.

In order to convert the measured signals into mass concentrations and size distributions a size calibration, an inlet flow calibration, and an ionization efficiency (IE) calibration were performed during the campaign. For conversion of the measured particle time-of-flight into $d_{v a}$ a calibration using ammonium nitrate particles of known diameters was performed as described below. Signal conversion into aerosol mass concentration was enabled by an ionization efficiency calibration using size-selected ammonium nitrate particles as described below. Finally an inlet flow calibration was performed to convert the measured pressure in the aerodynamic lens into a volumetric inlet flow rate. This was done by measuring the inlet flow with a bubble flow meter (Gilibrator-2, Sensidyne, Inc.) and the aerodynamic lens pressure for a series of inlet flow rates with the attached pressure gauge (MKS Baratron, 0-10 Torr (0-13.33 hPa)).

The PMTACS-NY 2004 campaign took place on campus of Queens College in Queens, New York $\left(40.74^{\circ} \mathrm{N}, 73.82^{\circ} \mathrm{W}\right.$, altitude $\sim 25 \mathrm{~m}$ a.m.s.l.) from January 8, 2004 until February 6, 2004. The measurement site was located in a one-story building next to parking lot \#6, about $100 \mathrm{~m}$ east of the measurement site of the PMTACS-NY 2001 summer campaign. The TOF-AMS was located in a room together with a Q-AMS, and both instruments shared a common inlet line. The inlet was at a height of $6.50 \mathrm{~m}$ above ground level, $1.50 \mathrm{~m}$ above the roof of the building. The aerosol was pumped through a $\mathrm{PM}_{2.5}$ cyclone (URG-2000$30 \mathrm{EN}$ ) and $14 \mathrm{~mm}$ ID copper tubing at a flow rate of $10 \mathrm{l} / \mathrm{min}$. Inside the building the inlet line was covered with $2 \mathrm{~cm}$ thick foam tube insulation to reduce heating of the sample before extraction into the instruments. First the Q-AMS extracted its inlet flow $(0.1 \mathrm{l} / \mathrm{min})$ from the total flow and several $\mathrm{cm}$ downstream of this sampling point the TOF-AMS extracted its inlet flow (also $0.1 \mathrm{l} / \mathrm{min}$ ). The total inlet line length from the cyclone to the inlet of the TOF-AMS was $7.6 \mathrm{~m}$. Diffusion, settling and inertial losses of particles in the size range $25 \mathrm{~nm}$ up to $1 \mu \mathrm{m}$ were estimated to be below $3 \%$ for any size for this inlet line.

\section{DATA PROCESSING}

The data collected in the three modes of operation of the TOFAMS were processed separately and provided redundant as well as complementary information. The MS mode is used to determine mass concentrations for several species: non-refractory sulfate, nitrate, ammonium, chloride and total non-refractory organics. The P-TOF mode data were used to determine the size distributions for each of these species. Finally the SP-TOF mode data give information about single particle composition and internal or external mixture of the species in the particles. Here we present the data processing strategies for the data of each of these modes separately.

\section{Mass Spectrum (MS) Mode Data}

The MS mode data were used to calculate mass concentrations for several species. In order to do this the first step is to extract a spectrum with unit mass resolution from the raw mass spectrum. This is equivalent to integrating the area under all the peaks in the mass spectrum. Note that the peak area is the physically meaningful measure of ion current in a TOF-MS, unlike for a quadrupole MS where peak height is the relevant measurement (Jimenez et al. 2003a). Using four prominent peaks in the mass spectra an accurate ion mass calibration was determined for each raw spectrum. An automated procedure detects the positions of maximum signal at the approximate locations of the peaks of $\mathrm{N}^{+}\left(m / z\right.$ 14.0067), $\mathbf{N}_{2}^{+}(m / z 28.0134), \mathrm{O}_{2}^{+}(m / z 31.9898)$, and $\mathrm{Ar}^{+}(m / z$ 39.948). In the extractor of the TOF-MS the ions are accelerated to a velocity $v$ by the flight tube voltage $U$ :

$$
q \cdot U=\frac{1}{2} m \cdot v^{2} \Rightarrow v=\frac{s}{t_{f}}=\sqrt{\frac{2 q U}{m}}
$$

where $t_{f}$ is the flight time of the ions in the TOF-MS (position of the peak in the mass spectrum), $s$ the effective drift length of the time-of-flight mass spectrometer $(430 \mathrm{~mm}), m$ the mass of the ion and $q$ the electric charge of the ion $q=z^{*} e$, where 
$z$ is the number of net elementary charges in the ion, and $e$ is the elementary charge. From Equation 1, the flight time of each ion is proportional to the square root of its $m / z$. In practice $t_{f}$ is replaced by the index $x$ of the $m / z$ in the $1 \mathrm{~ns}$ resolution mass spectrum. This results in the calibration equation for the TOF-MS:

$$
\sqrt{\frac{m}{z}} a \cdot x+b
$$

where $a$ and $b$ are calibration constants. Plotting the square roots of the exact $m / z$ of the four peaks versus their peak positions produces a straight line. The calibration constants were determined by fitting a line to these points. For a check of the quality and the temporal variation of the mass calibration a set of almost 800 mass spectra, recorded in MS mode and representing a 5-min average each was analyzed in greater detail. This analysis shows that the linearity of the mass calibration is extremely good for all spectra: The Pearson's $R^{2}$ is above 0.9999995 for all $\mathrm{m} / \mathrm{z}$ calibrations. Also the peak positions of the mass peaks are very well defined by the calibration. The relative uncertainty of the maximum signal position of the $m / z 32$ calibration peak $\left(\mathrm{O}_{2}^{+}\right)$defined as uncertainty of the peak position $\Delta m$ (total range of peak positions in $m / z$ ) divided by its mass $m$ is $3.6 * 10^{-4}$. The uncertainties $\Delta m / m$ of the other calibration peaks are all between $2.5 * 10^{-4}$ and $4.4 * 10^{-4}$.

The limits for the peak integration were defined by looking at a large number of peaks in a large number of averaged mass spectra and checking the area in the mass spectra the peaks are spread over. This resulted in the following limits: at $m / z 28$ the peaks were integrated in the range $m / z=-0.2$ to +0.2 around the nominal value for each $m / z$. Since the peak width (in mass units) increases with increasing $m / z$ a linear increase of the peak integration area was applied, which resulted in an integration range of -0.3 to +0.5 around the nominal value for each peak at $m / z 183$. The remaining part of the mass spectra between the peak integration areas was used for baseline calculation, which consequently decreased with increasing $\mathrm{m} / \mathrm{z}$. The baseline for each peak was calculated as the average value of the baseline range before and after the peak, in order to compensate for any baseline shifts over the peak. The peak area was defined as the sum of the measured value minus the average baseline value for all data points within the peak integration area. For calculation of the unit resolution spectra the peak areas for all $\mathrm{m} / \mathrm{z}$ were calculated for every mass spectrum automatically.

In a second step the unit resolution spectra were corrected for the ion-mass dependent extraction efficiency into the TOF-MS. As mentioned above the ions cross the TOF-MS extractor with a velocity that is inversely proportional to the square root of their mass-to-charge ratio, resulting in an extraction efficiency proportional to the square root of their mass-to-charge ratio. Using the signal at one $m / z$ (we used $m / z 28$ ) as a reference, the signal intensity of each $m / z$ was corrected for this effect. This correction accounts for velocity differences of the ions in the extrac- tor, however further effects like transmission efficiency through the electrostatic lens assembly or the TOF-MS as a function of mass-to-charge ratio are currently under investigation and are not accounted for yet.

The calculation of the signal for each species from the unit resolution spectra is closely related to the Q-AMS data processing procedures described in Jimenez et al. (2003a) and Allan et al. (2004). For calculation of the species-related signal intensity from the unit resolution spectra all the $m / z$ that contain fragments of this species were summed. Some of these $m / z$ also contain interfering signal from fragments of other species or isotopes of other $m / z$, and the signal of these $m / z$ was corrected for this. Allan et al. (2004) describes these corrections in detail. In addition to these corrections the species signal was multiplied by a factor that takes into account the relative ionization efficiency of the species $\left(R I E_{s}\right)$ in comparison to the calibration species (ammonium nitrate) as described in Jimenez et al. (2003a) and Alfarra et al. (2004). Finally a collection efficiency (CE) correction factor was applied that corrects for particle collection efficiency below $100 \%$. This factor corrects for effects such as incomplete focusing of the particle beam and for bounce of some particles from the vaporizer. It was determined by comparison of Q-AMS sulfate mass concentrations for a single week with sulfate mass concentrations measured with a co-located PILS-IC (Weimer et al. 2005). As discussed by Weimer et al. a common collection efficiency factor of $C E=0.42$ was assumed for all species for the Q-AMS, because it was assumed that the species were internally mixed for most of the time. There have been exceptions from this behavior that resulted in different collection efficiencies. These cases are discussed in detail in Weimer et al. (2005). To assure comparability with the Q-AMS data the same CE factor was used for the TOF-AMS as for the Q-AMS. Table 1 gives the values of the parameters used to calculate the mass concentrations of the main species.

The total species signal intensity was converted into mass concentrations using the ionization efficiency (IE) calibration performed later during the campaign. The ionization efficiency is the number of ions detected per molecule introduced into the instrument. In the $I E$ calibration the ionization efficiency is calculated by dividing the number of ions measured per particle introduced into the instrument (IPP, calculated as TOF-MS signal divided by particle number concentration $C_{n}$ and inlet flow rate $Q$, here only ions that were associated with nitrate were counted) divided by the number of molecules per particle, calculated from the selected particle mobility diameter $d_{m}$, the particle density $\rho_{p}$, and the molecular weight of the calibration substance:

$$
\begin{aligned}
I E & =\frac{\mathrm{IPP}_{\text {measured }}}{\text { Molecules per Particle }} \\
& =\frac{\text { Signal } \cdot \mathrm{MW}_{\mathrm{NO} 3}}{C_{n} \cdot Q \cdot N_{A} \cdot \rho_{p} \cdot \frac{\pi}{6} \cdot d_{m}^{3} \cdot S \cdot f_{\mathrm{NO} 3}}
\end{aligned}
$$

with the TOF-MS signal in ions per second $(\mathrm{Hz}), \mathrm{MW}_{\mathrm{NO} 3}$ the molecular weight of the calibration substance (nitrate from 
TABLE 1

Parameters used to calculate the species mass concentrations and size distributions from the unit resolution mass spectra, after correction for major known interferences at each $\mathrm{m} / \mathrm{z}$ from other species

\begin{tabular}{lllcc}
\hline Species & \multicolumn{1}{c}{$\begin{array}{c}m / z \text { used for } \\
\text { calculation }\end{array}$} & RIE & $\begin{array}{c}\text { Omitted } m / z \\
\text { correction }\end{array}$ & CE \\
\hline Nitrate & 30,46 & 1.0 & 0.96 & 0.42 \\
Sulfate & $48,64,80,81$ & 1.2 & 0.63 & 0.42 \\
Ammonium & $15,16,17$ & 3.78 & 1.0 & 0.42 \\
Organics & All other $m / z>11^{a}$ & 1.4 & 1.0 & 0.42 \\
\hline
\end{tabular}

In the size distributions the species signal is the sum of the fragments at the $m / z$ given in column 2 , divided by correction factors for relative ionization efficiency (RIE, column 3), for omitted fragments (column 4 ), and for collection efficiency of the particles (column 5). The mass concentrations were calculated from all $\mathrm{m} / \mathrm{z}$ that contain signal of fragments using the deconvolution scheme described in Allan et al. (2004). Here only RIE and CE correction factors were used.

${ }^{a}$ For calculation of the organics signal not all other $m / z$ were used; some $m / z$ such as 23 and 39 are not used due to poor S/N and interference from $\mathrm{Na}^{+}$and $\mathrm{K}^{+}$.

ammonium nitrate), $f_{\mathrm{NO} 3}$ is the fraction of nitrate in the particles (0.775), and $S$ the Jayne shape factor $(S=0.8)$ that corrects for actual particle density and shape (DeCarlo et al. 2004). For this calibration ammonium nitrate particles were generated by atomizing a $\mathrm{NH}_{4} \mathrm{NO}_{3}$ solution and selecting only a certain particle size with a DMA (TSI, Model 3080). The aerosol was directed into the TOF-AMS and a condensation particle counter (TSI, Model 3025) in parallel. The length of the sampling line between the DMA and the TOF-AMS inlet was kept as short as possible to minimize evaporative shrinking of the particles that would result in low IE values. To avoid a large contribution from multiply charged particles the particle sizes were selected to be above the mode of the primary particle size distribution generated with the atomizer. This measurement was done for several particle sizes. In Figure 3 the measured TOF-MS nitrate signal (in $\mathrm{Hz}$ ) is plotted versus the nitrate mass concentration calculated for each measurement from the $\mathrm{CPC}$ number concentration and the selected particle mobility diameter. Using Equation 3 the slope of the linear fit (constrained to zero intercept) through these measurement points is converted into the ionization efficiency of the TOF-AMS for nitrate, which is comparable to ionization efficiencies measured with the Q-AMS.

The error bars shown in the $I E$ calibration plot represent the estimated errors of this calibration: The measurement error of the mass spectrometer due to fluctuations of voltages and the filament current, particle losses in the instrument, and counting statistics was estimated to be $10 \%$. There is an additional uncertainty in the conversion of the TOF-MS raw signal into the signal in ions per second. However, this uncertainty cancels out when aerosol mass concentrations are calculated and therefore is not considered here. The error in calculated mass

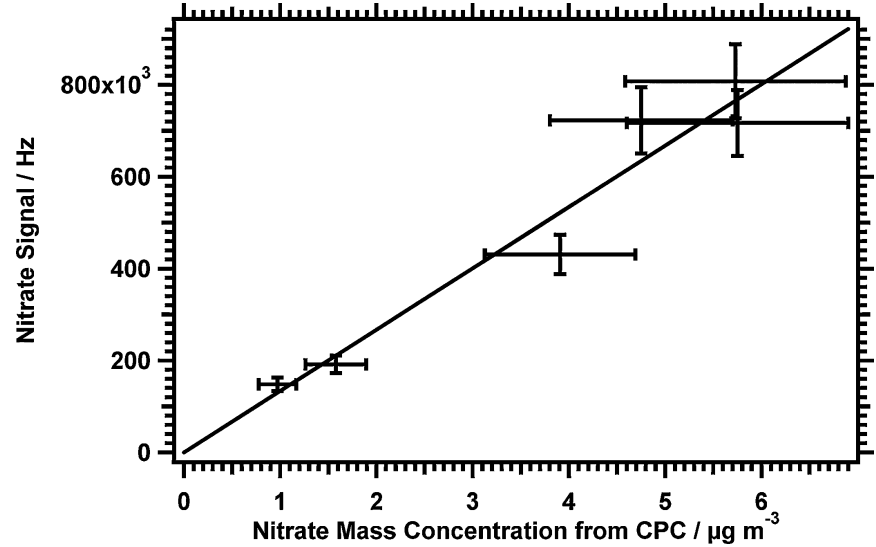

FIG. 3. Results of the ionization and detection efficiency (IE) calibration. Ammonium nitrate particles were generated with an atomizer and a DMA. Nitrate mass concentrations were calculated from particle number concentration and size and correlated with the nitrate signal of the TOF-AMS.

concentration is given by the uncertainty of the selected particle size and the error of the particle number concentration measurement. With an uncertainty of the selected particle size of $3 \%$ the resulting error in the calculated mass concentration is $9 \%$. The particle number concentration was determined manually by averaging several CPC readings over $5 \mathrm{~min}$. We assume that this procedure results in an uncertainty of $10 \%$ due to fluctuations of the particle source, the manual averaging (using a pocket calculator and averaging as many readings as possible within $5 \mathrm{~min}$ ) and the uncertainty in the absolute calibration of the CPC. In addition to these uncertainties the calculated particle mass concentration underestimates the real mass concentration introduced into the instrument due to a small fraction of multiply charged particles being transmitted through the DMA. We estimate the total uncertainty of the calculated mass concentrations from all sources to be $20 \%$. With these uncertainties the total uncertainty of the $I E$ calibration is $22 \%$. In order to perform accurate mass concentration measurements with the TOF-AMS this uncertainty needs to be reduced. A significant reduction of the uncertainty of the $I E$ calibration is obtained when the Q-AMS calibration routine is applied, where the averaged signal from individual particles of known size is determined. However, in order to implement this calibration scheme several additions to the TOF-AMS data acquisition software are necessary.

Due to a different $I E$ calibration routine the $I E$ determined for the TOF-AMS was slightly larger than it would have been with the Q-AMS IE calibration routine. This is because the $I E$ calibration performed with the Q-AMS is done in TOF-mode, where the measured ion signal is lower compared to the MS mode as a result of partial slow evaporation in the ms range. The $I E$ calibration for the TOF-AMS is performed in MS mode where measurements were made with $5 \mathrm{~s}$ time intervals between opening and closing of the aerosol beam and evaporation effects in the ms range do not affect the intensity of the ion signal. This 
difference is accounted for by multiplying the measured TOFAMS ionization efficiency with the ratio of Q-AMS TOF mode divided by MS mode signal, measured during the $I E$ calibration of the Q-AMS.

The calculation of mass concentrations from the raw signals assumes constant inlet flow, constant gain of the MCP detector, and no change in the ion extraction and analysis efficiency for the whole measurement time period. Neither is the case in the real world. However decay of the detector gain and changes in ion extraction/analysis efficiencies are taken into account by the "air beam" correction. Here it is assumed that the number of molecules of air reaching the detector per unit time is constant. The signal at $m / z 28\left(\mathrm{~N}_{2}^{+}\right)$is used as a measure of the air signal intensity (air beam signal). This signal will change proportionally to any change in the inlet (mass) gas flow rate and to any detection efficiency changes. The mass flow rate, which is determined by measuring the pressure in the aerodynamic lens, changes proportionally to the ambient pressure and in addition when the pinhole that regulates the inlet flow gets (partially) clogged. Since the data acquisition software was not prepared to monitor the inlet flow rate, this was checked manually several times per day. Here, no clogging of the pinhole was observed during this campaign. Due to the lack of continuous inlet flow rate measurements no corrections of the air beam for pressureinduced changes of the inlet mass flow rate were made. This causes an uncertainty in calculated mass concentrations in the order of less than $3 \%$, which is well within the uncertainty of the whole system at this time. Correction of all mass spectra that result in the same air beam signal as during the mass concentration calibration results in mass spectra free from influences due to detection efficiency changes.

\section{Averaged Particle Time-of-Flight (P-TOF) Mode Data}

The P-TOF mode data were used to calculate size distributions for each species independently. Transformation of the raw mass spectra collected in P-TOF mode into unit resolution spectra was done in a similar way as described for the MS mode data processing above. For calculation of the particle size $d_{v a}$ from the particle flight time (encoded in the position of the spectrum within the matrix) a particle time-of-flight calibration was used. In this P-TOF calibration ammonium nitrate particles of several sizes were generated using an atomizer (TSI, model 3076) and a DMA (TSI, model 3080) in series. The DMA had been calibrated with PSL spheres prior to the campaign. This aerosol was measured in the P-TOF mode. The velocities of all measured particles were calculated from the positions of the resulting mode diameters for the measured size distributions within the matrix, and plotted versus the vacuum aerodynamic diameter $d_{v a}$ of the particles. $d_{v a}$ is calculated from the particle mobility diameter $d_{m}$, the bulk density of the particle material $\rho_{m}$ and the Jayne shape factor $S$ (Jimenez et al. 2003b; DeCarlo et al. 2004):

$$
d_{v a}=\frac{\rho_{m}}{\rho_{0}} \cdot S \cdot d_{m}
$$

with $\rho_{0}$ the unit density $\left(1 \mathrm{~g} / \mathrm{cm}^{3}\right)$. The Jayne shape factor $(S)$ is determined for a certain particle composition and relative humidity in laboratory experiments by comparison of particle flight times of these particles and of spherical particles of known size and density like polystyrene latex (PSL) spheres.

In Figure 4 the P-TOF calibration plot is shown with the particle velocities plotted versus the $d_{v a}$ for the calibration particles. The data points were fitted with the following equation, given by Allan et al. (2003):

$$
v=v_{l}+\frac{v_{a}-v_{l}}{1+\left(\frac{d_{v a}}{d^{*}}\right)^{b}}
$$

where $v_{l}$ is the asymptotic velocity of particles with large $d_{v a}$ in $m / s, v_{a}$ is the asymptotic velocity of particles for $d_{v a} \rightarrow 0$ in $\mathrm{m} / \mathrm{s}$, and $d^{*}$ and $b$ are calibration parameters. The calibration parameters from the fit of (5) to the calibration data points are given in the plot. Using these calibration parameters the particle vacuum aerodynamic diameter is calculated from the particle velocity with:

$$
d_{v a}=\left(\frac{v_{g, a}-v_{g, i}}{v-v_{g, i}}-1\right)^{1 / b} \cdot d^{*}
$$

For calculation of the size distribution for a given $m / z$, its baseline (background signal intensity) needs to be subtracted in all spectra. For most $m / z$ the baseline is calculated from a linear fit through the averages of several data points at the beginning and end of the time-of-flight distribution. These point ranges were selected so that they do not contain significant signal from the size distribution. For $m / z$ 's that have contributions from the air beam species (e.g. $m / z 14\left(\mathrm{~N}^{+}\right), m / z 16\left(\mathrm{O}^{+}\right.$or $\left.\mathrm{NH}_{2}^{+}\right), m / z$ $18\left(\mathrm{H}_{2} \mathrm{O}^{+}\right), m / z 28\left(\mathrm{~N}_{2}^{+}\right), m / z 32\left(\mathrm{O}_{2}^{+}\right), m / z 40\left(\mathrm{Ar}^{+}\right)$, or $m / z$ $\left.44\left(\mathrm{CO}_{2}^{+}\right)\right)$the points at the beginning of a P-TOF cycle cannot be used for baseline calculation, since the gas-phase signal is present there. For these $m / z$ only the baseline points for large P-TOFs (corresponding to $d_{v a}$ larger than can be transmitted to the vaporizer) can be used and a horizontal baseline was assumed.

The size distributions of the individual species were calculated from the P-TOF distributions of the $m / z$ shown in Table 1. Since P-TOF distributions for all $\mathrm{m} / \mathrm{z}$ are available (unlike for the Q-AMS, in which only a small subset are available) the same scheme of calculation of the species size distribution can be used as for calculation of a species mass concentration as described above in the MS mode data processing section. Only the organics size distributions were calculated in a different way, only using the most prominent (high signal-to-noise) $\mathrm{m} / \mathrm{z}$ for calculation. This was done to avoid introduction of a significant amount of noise by averaging the $m / z$ size distributions of organic $m / z$ 's with high instrument background and low signal-to-noise. For display size distributions were plotted as traces of averaged size distributions of individual species for a given time interval or as 


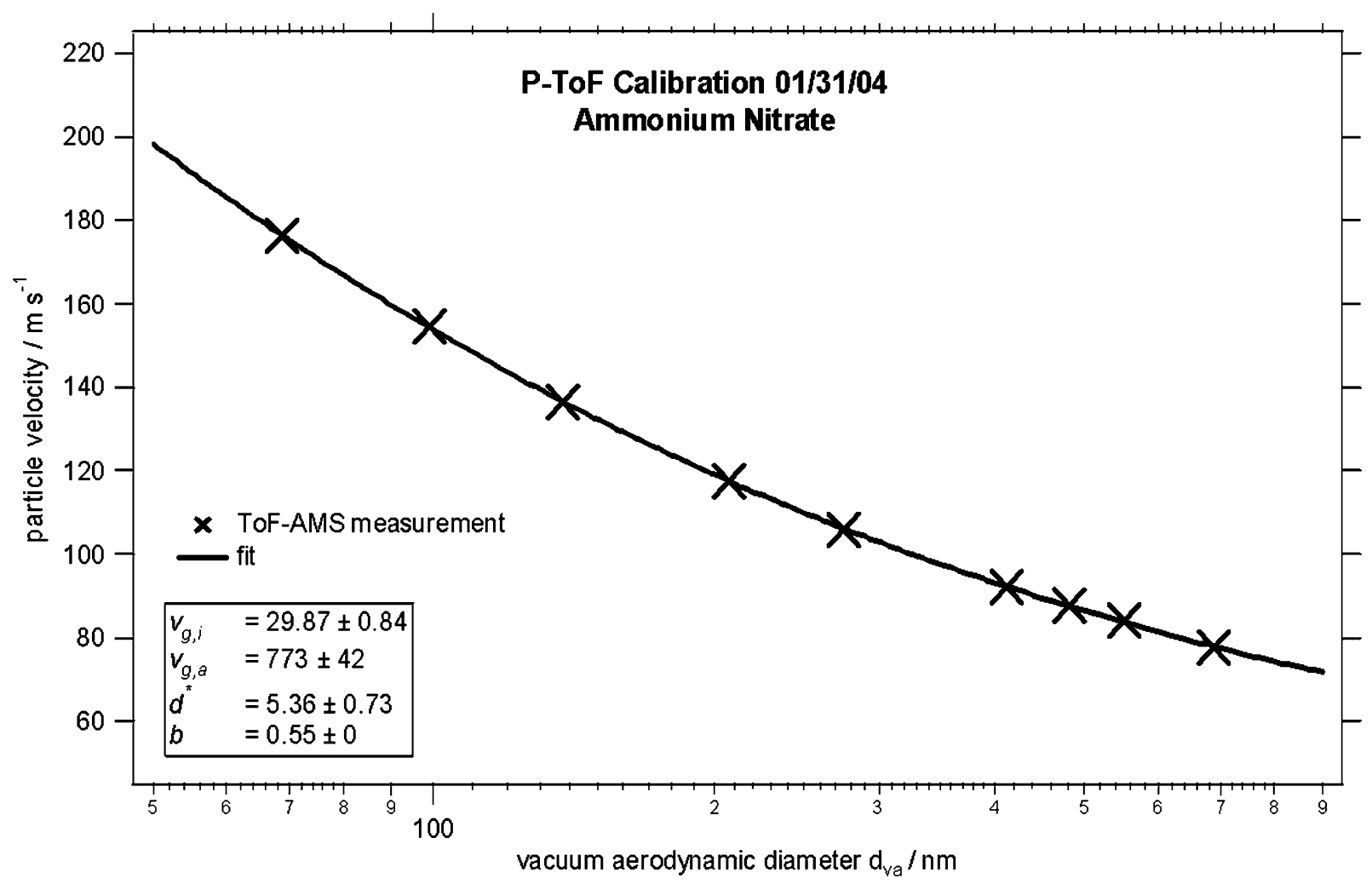

FIG. 4. Particle time-of-flight (size) calibration for the TOF-AMS. Ammonium nitrate particles of known size were generated with an atomizer and a DMA and measured with the TOF-AMS in P-TOF mode. The measured particle velocity is plotted versus the vacuum aerodynamic diameter of the particles, calculated from their mobility diameter and their known Jayne shape factor. The calibration parameters displayed in the insert are used to calculate particle size from particle time-of-flight.

image plots showing the temporal evolution of the size distribution of a certain species.

\section{Single Particle Time-of-Flight (SP-TOF) Mode Data}

The SP-TOF mode data were used to obtain size and composition information about individual aerosol particles. To reduce the enormous amount of data in a first step all the signal only containing noise was removed by extracting the "single particle events" by using a thresholding algorithm. The noise level in the spectra was determined by extracting only events within a three mass spectra wide sliding window that exceed thresholds for individual masses or combination of masses and plotting the total particle-related ion signal of the single particle events versus the diameter of the individual associated particles. Using this procedure the threshold levels for the individual ions were increased until most of the single particle events that are only caused by noise disappeared and only events that are associated with real particles are left as shown in Figure 5.

For identification of a single particle event the signal had to exceed the single particle threshold for either one of the $\mathrm{m} / \mathrm{z}$ associated with either nitrate $(m / z 30,46)$, sulfate $(m / z 48,64)$, organics $(m / z 43,44,55,57,69,71)$ or for a combination of these $m / z$ with a larger threshold level. Manual inspection of the
SP-TOF mode data showed that typical single particle events are approximately $2-5$ spectra $(\mathrm{P}-\mathrm{TOF}=48-120 \mu \mathrm{s})$ wide in a P-TOF cycle, which is consistent with what is observed in the Q-AMS (Jayne et al. 2000). This was to be expected since that timescale is determined by the timescales of particle vaporization and for the vaporized molecules to leave the ionizer region, which should be exactly the same in the Q-AMS and TOF-AMS due to the use of the same vaporization/ionization components. In order to cover the whole single particle event, for every threshold crossing the signal maximum of the event was located and the average mass spectrum for this event was calculated from this mass spectrum plus the two mass spectra on each side of the center position (P-TOF -48 to $+48 \mu \mathrm{s}$ ). Finally from every single particle event an average background signal was subtracted that was calculated from 500,000 mass spectra from the P-TOF range of the SP-TOF data where no particles are expected (related $d_{v a}$ below cut-off diameter of TOF-AMS inlet) Collection of the single particle events from all SP-TOF mode data reduced the amount of data by almost 3 orders of magnitude to $4 \mathrm{MB}$, which can be easily handled within a single data matrix in PC memory.

Size distributions as well as average mass spectra can be easily calculated from all SP-TOF mode data as well as from all single particle events using the procedures described for the 


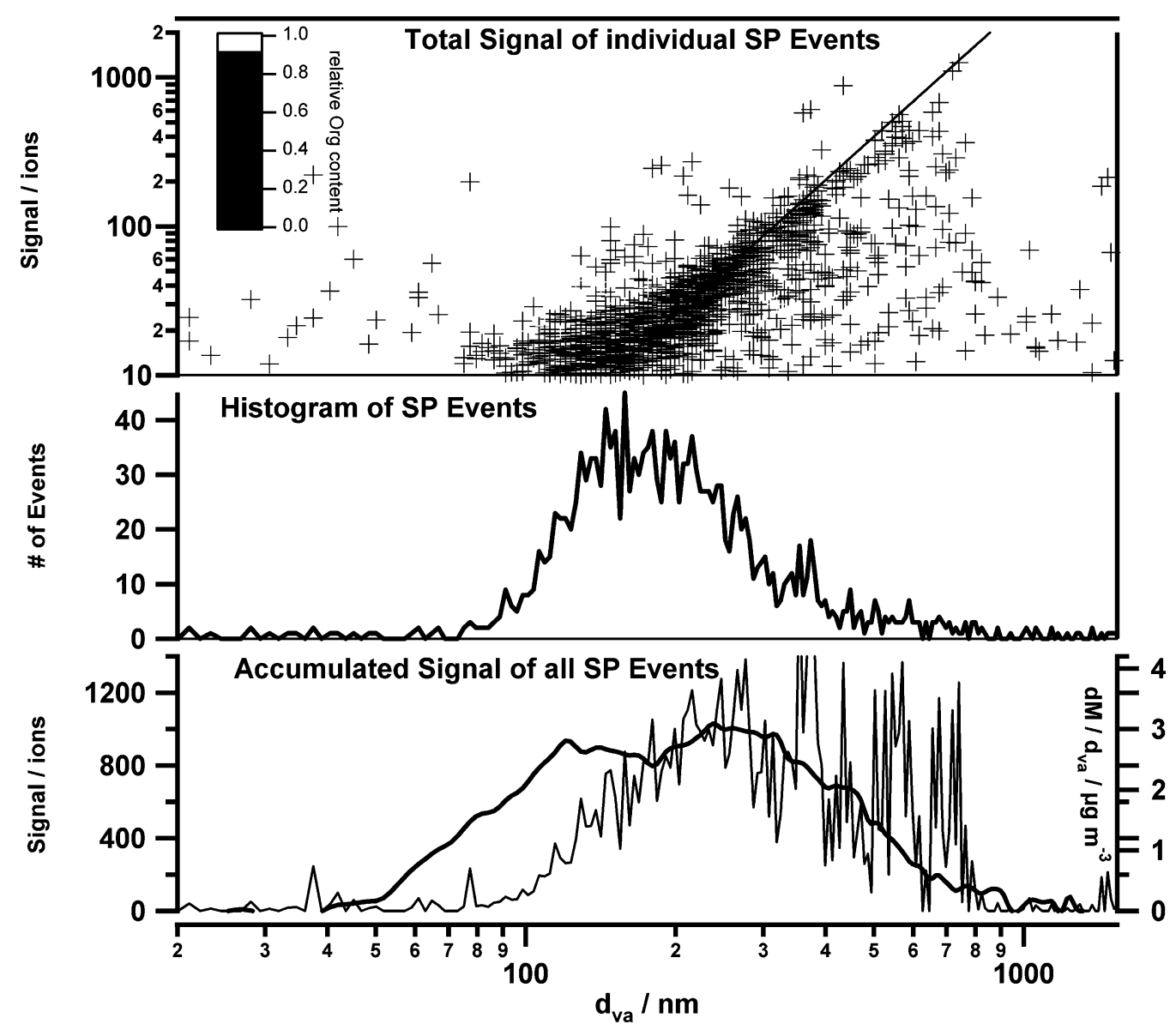

FIG. 5. Total particle-related ion signal plotted versus particle diameter $d_{v a}$ for all extracted single particle events (top panel). The markers are shaded according to the relative organics content of the particles. Most of the single particle events contain a significant amount of inorganic species. The histogram of SP-events (middle panel) shows that about $97 \%$ of all extracted SP-events are associated with real particles. The average size distribution calculated from the total ion signal of all SP-events agrees well with the average P-TOF size distribution for the days of SP-TOF measurements for particles with $d_{v a}>150 \mathrm{~nm}$ (lower panel).

P-TOF and MS modes. Information about internal or external mixture of species within the particles is obtained by calculating the individual species signal for every single particle from the averaged single particle event mass spectra and correlating different species signals with each other for a large number of single particle events. Due to the poor ion counting statistics within a single particle mass spectrum, the total species signal was calculated from the averaged single particle mass spectrum with a simplified version of the method described above: Only the most prominent fragments were used and only corrections for very large contributions from the air beam were performed. Nitrate was calculated as $m / z 30+46$, sulfate was calculated as $m / z 48+64+80+81$, and so on. This procedure reduced the matrix of single particle events into data series for the species nitrate, sulfate, ammonium, organics, and in addition for the signal at $m / z 57$ and $m / z 44$ which are important markers for certain organic aerosol types (Zhang et al. 2005). By plotting these data series versus each other in scatter plots, internal or external mixtures of species are identified.

\section{RESULTS}

During PMTACS-NY 2004 the TOF-AMS collected data starting from January 13 to February 1. Data collection was performed in different modes of operation or a combination of them. Data were not obtained during several time intervals due to calibrations, instrument repair (broken vaporizer), or instrument and software testing and maintenance.

\section{Mass Concentration Data}

The MS mode data were processed and transformed into time series of species mass concentrations as described above. The time series need to be divided into four periods: Period \#1: 01/13 22:03-01/15 11:04; Period \#2: 01/17 00:02-01/21 10:07; Period \#3: 01/28 09:25-01/31 11:30; Period \#4: 01/31 14:13-02/01 $08: 33$. The time resolution of the data is about five minutes for most of the campaign.

At the end of period \#3 an ionization efficiency (IE) calibration was performed. After the end of period \#1 the instrument 
was disassembled for exchange of the vaporizer because it was not able to reach the standard operating temperature $\left(\sim 600^{\circ} \mathrm{C}\right)$.

After application of all corrections the resulting mass concentrations in the four periods compare differently to Q-AMS mass concentrations in the various intervals. The difference between periods \#1 and 2 was caused by the exchange of the vaporizer, which changes the vaporization/ionization geometry and vaporizer temperature, resulting in a change of ionization efficiency. Another systematic difference between periods \#2 and 3 is probably caused by the change to different data acquisition software. The changes between periods \#3 and 4 are suspected to be due to a malfunction of the Q-AMS during the last time interval. Since only for period \#3 a valid $I E$ calibration exists, we exclude period \#1, 2, and 4 from further analysis and discuss only data from period \#3. However each period is internally consistent and these changes, mostly due to the very early state of development of the TOF-AMS during this campaign, should be eliminated or can be calibrated for in future field campaigns.

Since this is the first deployment of the TOF-AMS in a field study, a direct comparison of TOF-AMS data with measurements performed with the co-located Q-AMS will validate the capability of the TOF-AMS to measure aerosol mass concentrations and size distributions. In Figure 6 a direct comparison of nitrate, sulfate, ammonium and organics mass concentrations
TABLE 2

Parameters of the correlations and linear regressions between the TOF-AMS and Q-AMS mass concentration data for nitrate, sulfate, ammonium, and organics calculated for period \#3

\begin{tabular}{lcccc}
\hline Species & Slope & Intercept $/ \mu \mathrm{g} \mathrm{m}^{-3}$ & Recovery & $\mathrm{R}^{2}$ \\
\hline Nitrate & 0.88 & 0.11 & 0.91 & 0.93 \\
Sulfate & 0.68 & 0.29 & 0.78 & 0.84 \\
Ammonium & 0.64 & 0.32 & 0.82 & 0.95 \\
Organics & 0.46 & 0.06 & 0.47 & 0.80
\end{tabular}

for both instruments is shown by plotting their time series of mass concentrations for the time interval of period \#3 TOFAMS measurements. The complete time series of mass concentrations measured with the Q-AMS during the whole campaign together with a discussion of the measured aerosol will be given in Weimer et al. (2005). In Figure 7 scatter plots of mass concentrations measured with the TOF-AMS during period \#3 plotted versus Q-AMS mass concentrations for nitrate, sulfate, ammonium and total organics are shown. In Table 2 the parameters of the correlations and linear regressions are shown for each species individually.

As shown in Figure 7 and Table 2 the strength of the correlations of the two instruments for the period presented here is very good for nitrate and ammonium with $R^{2}$-values around 0.95 . The

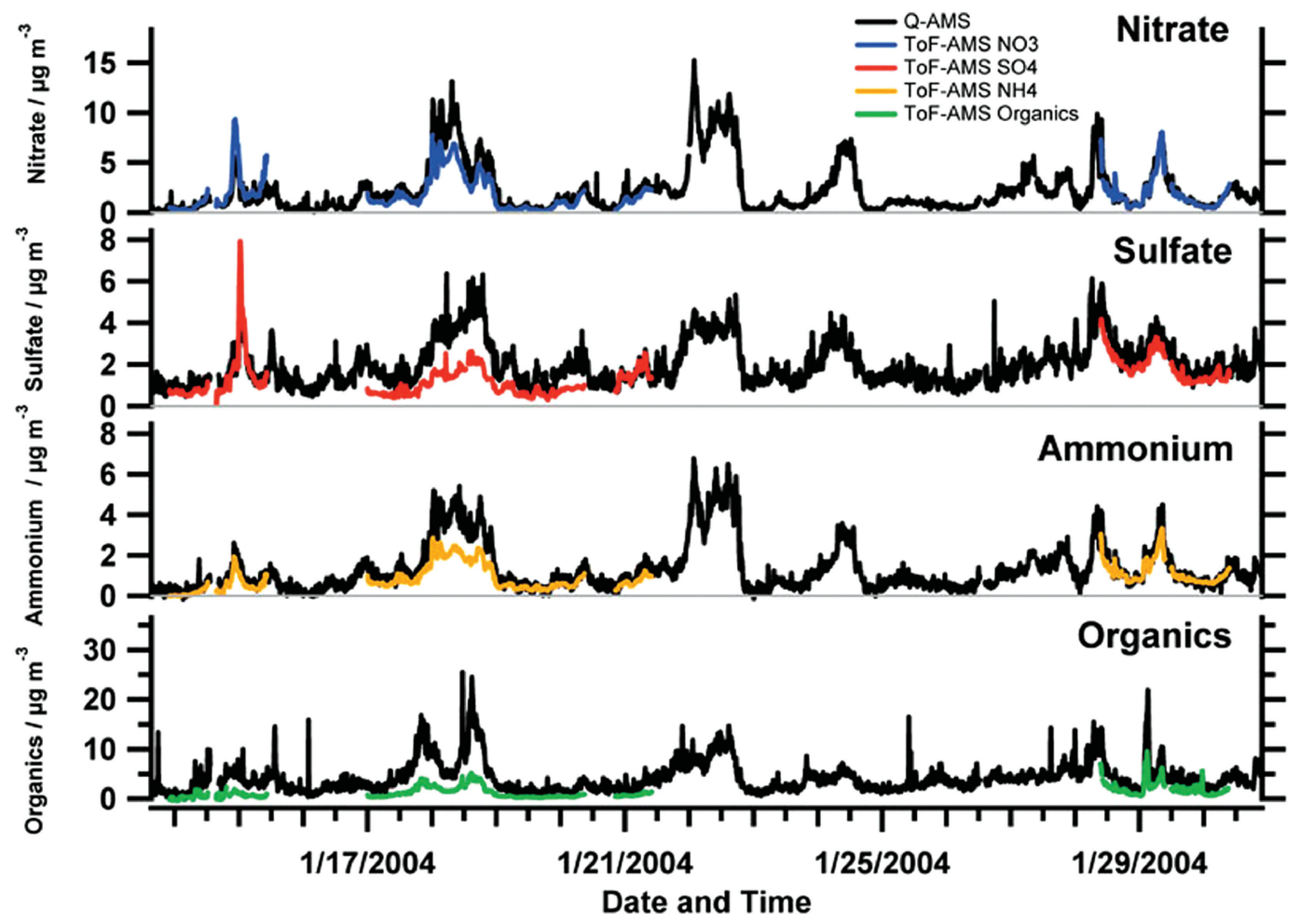

FIG. 6. Time series of non-refractory nitrate, sulfate, ammonium and total non-refractory organics measured with the TOF-AMS (blue, red, orange, green) and the Q-AMS (black) for the same time interval during measurement period \#3 of the TOF-AMS. 

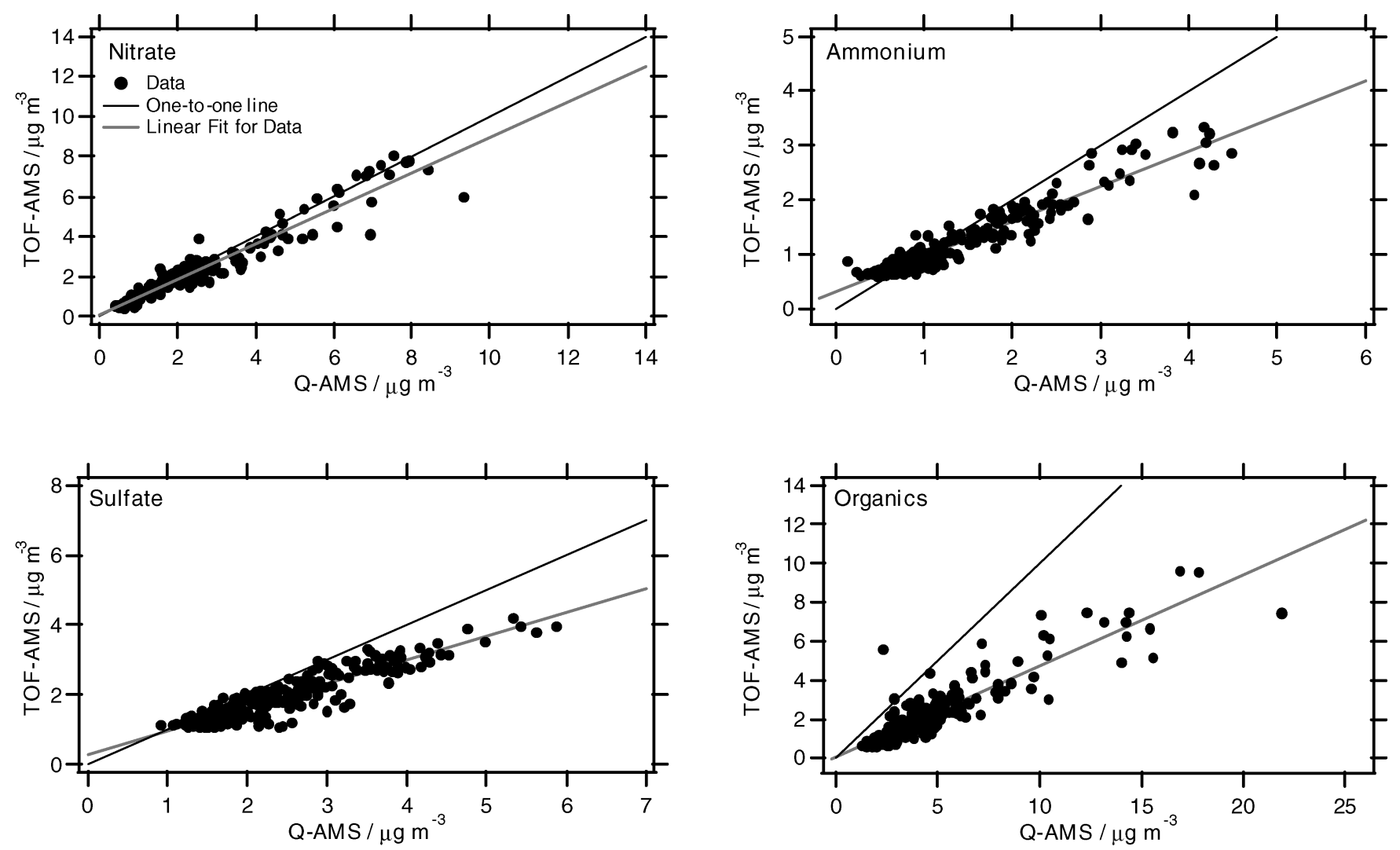

FIG. 7. Comparison of the mass concentrations measured with the TOF-AMS and the Q-AMS for period \#3.

correlations for sulfate and the total organics signal are slightly broader but still very good with $R^{2}$ of 0.84 and 0.80 , respectively. The slopes of the regression lines are in the range of 0.46 to 0.88 with positive intercepts ranging from 0.06 to $0.32 \mu \mathrm{g} / \mathrm{m}^{3}$. For direct comparison "recoveries" (slope of correlation with intercept forced through zero) were calculated for each species. They are 0.47 for organics, 0.78 for sulfate, 0.82 for ammonium, and 0.91 for nitrate. This means that for the inorganic species approximately $80-90 \%$ of the mass concentrations of the individual species measured with the Q-AMS were detected with the TOFAMS. For organics only $50 \%$ of the Q-AMS mass concentrations were measured with the TOF-AMS. While the measured mass concentrations of nitrate, sulfate, and ammonium agree with the Q-AMS measurements within the uncertainty of the TOF-AMS IE-calibration, for organics significantly lower concentrations were measured with the TOF-AMS. Only a small fraction $(<3 \%)$ of this difference can be explained by transport losses of particles in the sampling line between the Q-AMS and the TOF-AMS. Another small part $(\sim 5 \%)$ of the low organics mass concentrations is due to the fact that TOF-AMS organics is the sum of signal measured up to $m / z 206$, while in the Q-AMS the ion signals up to $m / z 300$ are added to calculate organics mass concentrations. In future comparisons of the TOF-AMS this difference should also be removed by calculation of or- ganic mass concentrations from the same $m / z$ range in both instruments. Another small part of the differences may be due to small differences in vaporizer temperature or electron energy in the two instruments. Subsequent results from laboratory and field tests indicate that several of the ionizer and TOF-MS voltages were not optimally tuned during the PMTACS-NY 2004 campaign. This resulted in a decrease in ion transmission with increasing $m / z$, thus reducing the total signal for those species that have higher $m / z$ ions associated with them: organics and to a smaller extent sulfate. Nevertheless, both TOF-AMS sulfate and organics show a strong correlation with the same species measured by the Q-AMS, suggesting that there are no further issues affecting the detection of these species.

In summary the data presented in Figures 6 and 7 as well as in Table 2 show that the TOF-AMS in principle is capable of reliably measuring mass concentrations with high time resolution, that correlate well with measurements of the Q-AMS. Since we assume that a significant part of the observed differences are due to suboptimal tuning of the TOF-AMS during this campaign, and to the larger uncertainties in the $I E$ calibration of the TOF-AMS, for better quantification further improvements of this calibration routine have to be developed, which is being addressed by current laboratory experiments (Hings et al. 2005) and additions to the data acquisition software. 


\section{Averaged Size Distributions}

P-TOF mode data were collected during a total of 12 time intervals from January 22 until February 1. The data from January 22 until January 27 were collected in P-TOF mode only, while the data starting from January 28 were collected in the P-TOF/MS alternate mode. Time resolution of all data is approximately five minutes. The gaps between the data sets are caused by maintenance on the data acquisition program, by calibrations, and by time periods dedicated to SP-TOF mode acquisition.

The P-TOF mode data were processed as described above to generate 5-min averages of the size distributions for nitrate, sulfate, ammonium and organics. As an example, showing the sensitivity of the TOF-AMS measurements the temporal evolution of the nitrate size distribution is shown for a period of 10 hours as image plots in Figure 8 for data collected with the TOF-AMS and with the Q-AMS. The data shown in this figure are 5-min data for the TOF-AMS and 10-min data for the Q-AMS, both without any smoothing of the data.
Even though the image plots of the size distributions from the two instruments have differences of detail, they both agree well in the temporal evolution of the size distributions, the absolute sizes of the particle modes as well as in the absolute intensity of the modes. Despite the fact that the Q-AMS data are averages over $10 \mathrm{~min}$ while the TOF-AMS data are averaged over 5 min each, the size distribution time series generated from the TOF-AMS shows significantly less noise and is much smoother than the Q-AMS image plot. This results in better resolution of features within time as well as within size. Several features that are blurred in the Q-AMS size distribution time series are clearly seen in the size distributions measured with the TOF-AMS. This reduction in noise is mainly a result of significantly improved particle statistics in the TOF-AMS size distribution measurements, compared to those performed with the Q-AMS: While in the Q-AMS a size distribution for a single $m / z$ is measured at a time the TOF-AMS is capable of measuring all $\mathrm{m} / \mathrm{z}$ size distributions in parallel. The theoretical study and experimental quantification of how this improvement in particle duty cycle
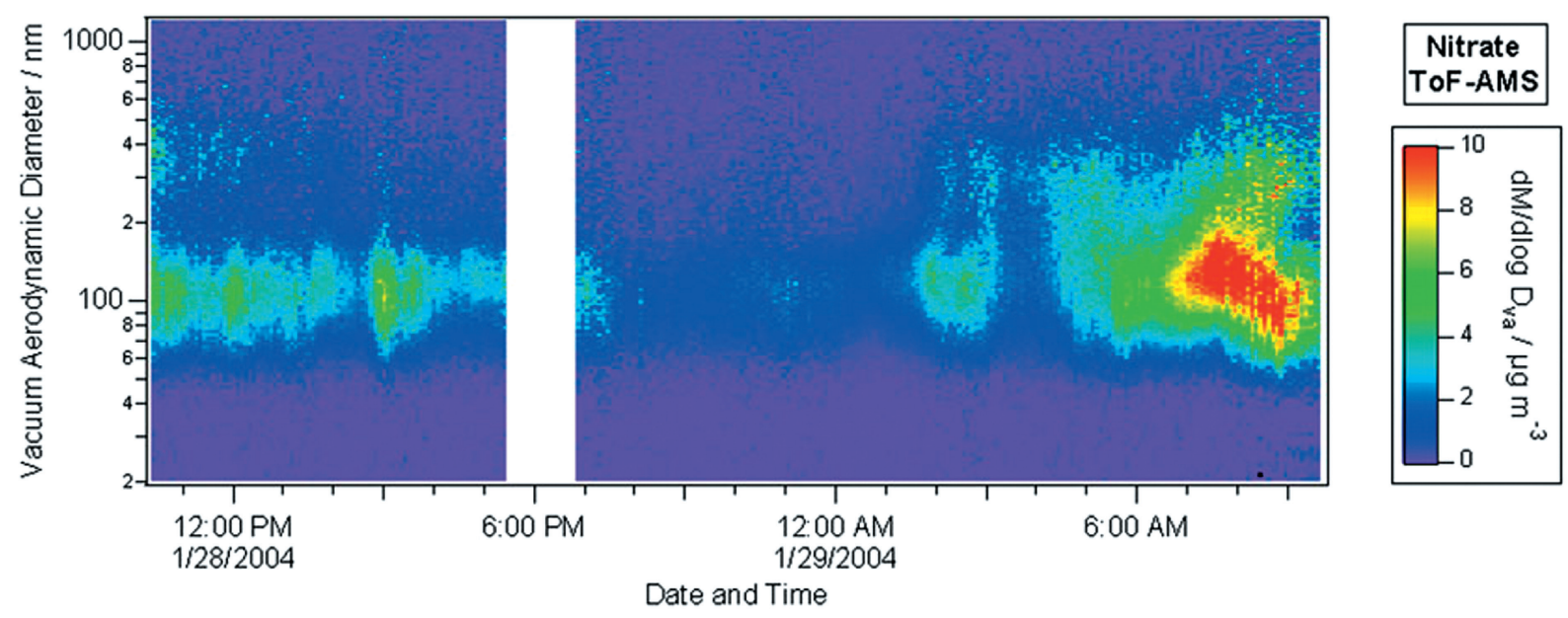

Date and Time
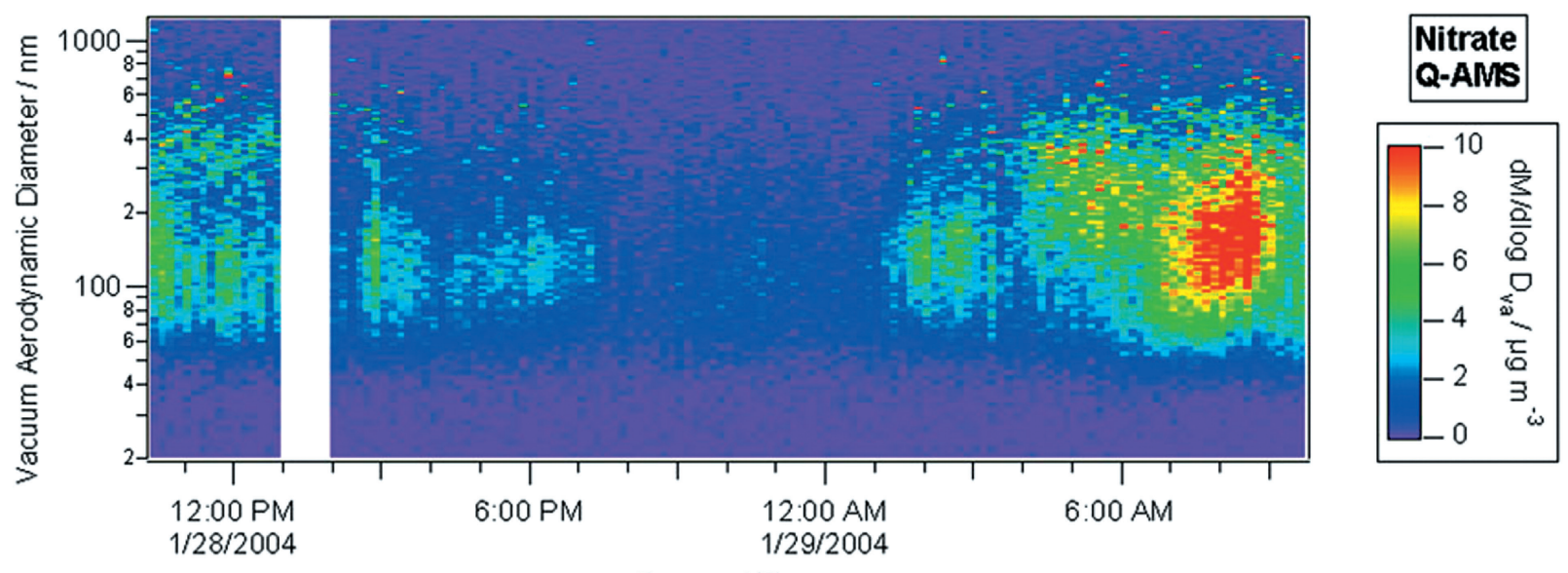

Date and Time

FIG. 8. Temporal evolution of the nitrate size distribution measured with the TOF-AMS (top) and Q-AMS (bottom), shown for the time interval January 28 10:20 until January 29 09:45. The intensity of the signal bins is color-coded as shown in the legend. The TOF-AMS data shown in this Figure are 5-min averages; the Q-AMS data are 10-min averages. All data are shown without any smoothing. 

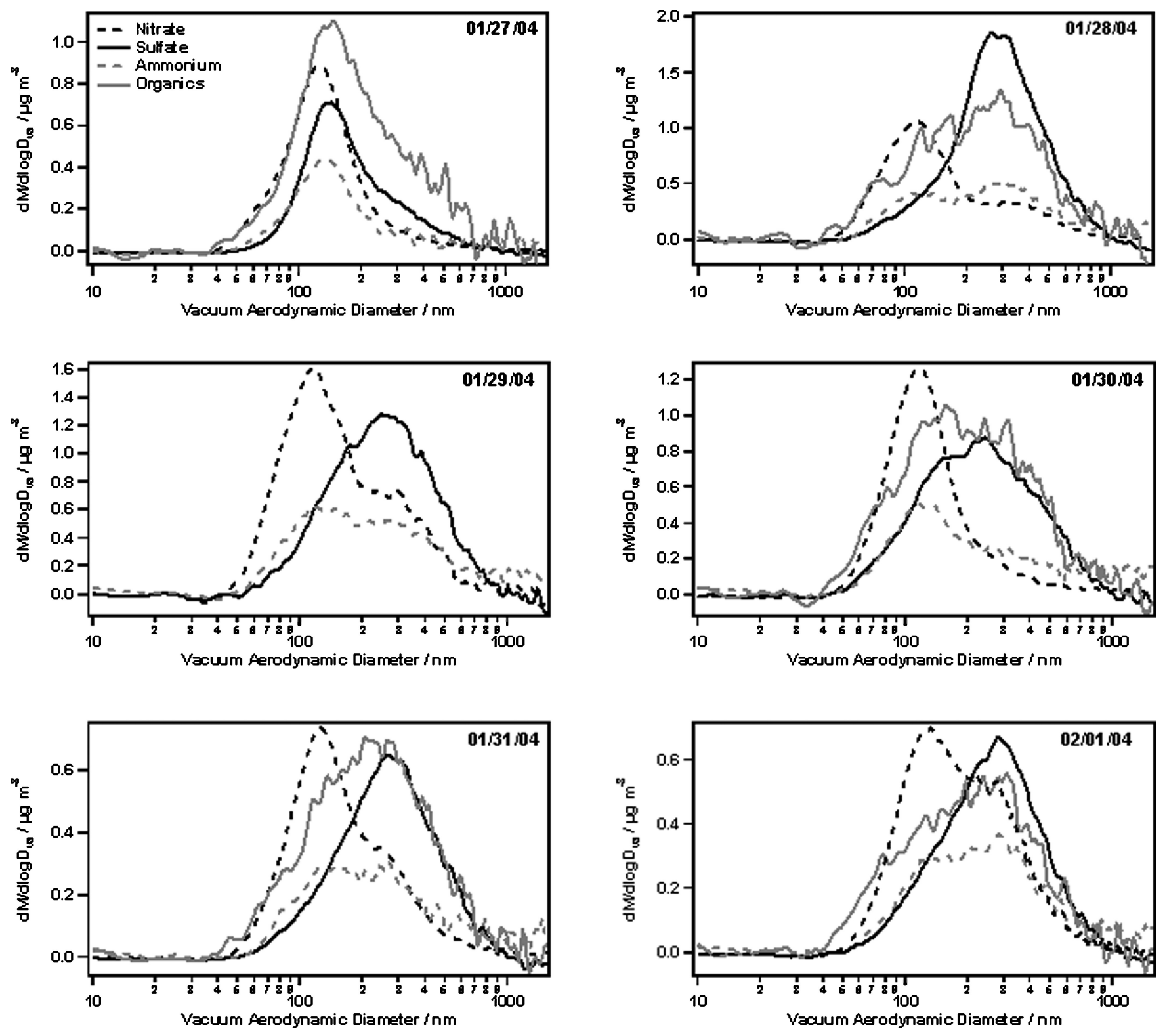

FIG. 9. Average size distributions for the last six days of the TOF-AMS deployment, shown for nitrate, sulfate, ammonium, and organics. The size distributions are plotted as traces of $\mathrm{dM} / \operatorname{dlog}_{10} d_{v a}$ versus particle vacuum aerodynamic diameter. The species-resolved size distributions suggest—with the exception of January 27-a partial external mixture of nitrate and sulfate particles.

results in improved sensitivity of the TOF-AMS measurements is subject of current laboratory experiments (Hings et al. 2005).

Average size distributions for the last six days of the TOFAMS deployment are shown for nitrate, sulfate, ammonium and organics in Figure 9. The size distributions are plotted as traces of $\mathrm{d} M / \mathrm{dlog}_{10} d_{v a}$ vs. $d_{v a}$. The species-resolved size distributions suggest-with the exception of January 27-a partial external mixture of nitrate and sulfate particles: For the days of January 28 until February 1 the main part of the nitrate size distribution is found at significantly smaller particle diameters than the sulfate size distribution. For most of these days the nitrate size distribution shows a small second mode located at the same particle size as the sulfate mode. This second mode could be due to a subpopulation of the nitrate that is internally mixed in the sulfate particles.

The ammonium size distribution is a combination of the nitrate and sulfate size distributions with two more or less separated modes, depending on the separation of the sulfate and nitrate modes. The organic size distributions are broader than the nitrate or sulfate size distributions. They seem to be 

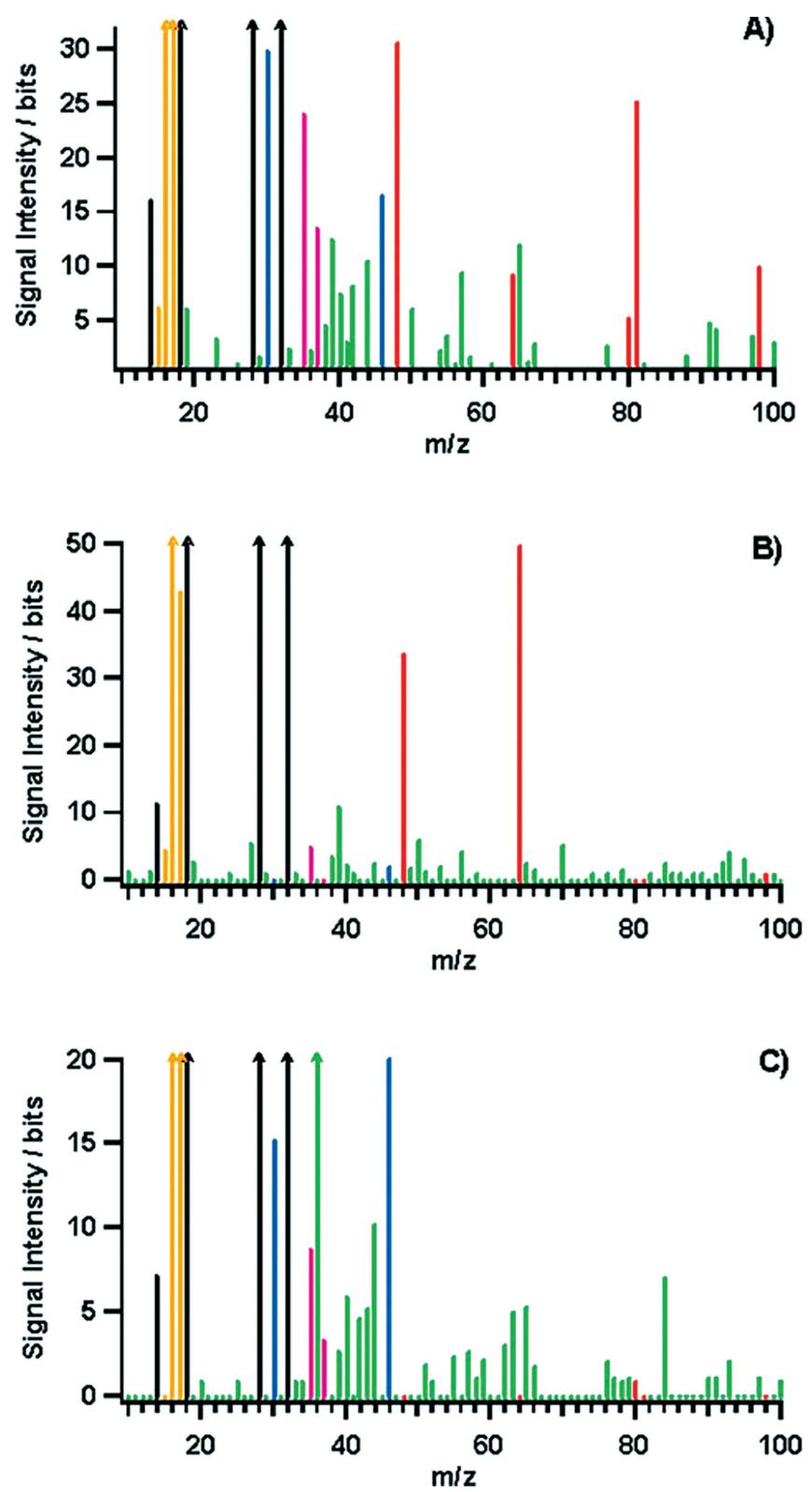

FIG. 10. Examples of averaged single particle event mass spectra. (A) Internally mixed ammonium nitrate/ammonium sulfate particle with organics and chloride $\left(d_{v a}=405 \mathrm{~nm}\right)$; (B) "Pure" ammonium sulfate particle $\left(d_{v a}=\right.$ $315 \mathrm{~nm}$ ); (C) Ammonium nitrate particle with some organics and chloride $\left(d_{v a}=\right.$ $190 \mathrm{~nm}$ ). The signal of the individual $\mathrm{m} / z$ is colored according to the species they belong to: air beam components (black), ammonium (orange), nitrate (blue), sulfate (red), and chloride (purple).

more associated with the sulfate size distributions. However, more information about internal or external mixture of aerosol components is found in the single particle data. An extensive discussion of the species-resolved average size distributions, measured during the PMTACS-NY 2004 and its association with sources will be given in Weimer et al. (2005).
Single Particle Data

SP-TOF mode data were collected during 13 time intervals distributed over the 5 days from January 27 until January 31 . Extracting only the single particle events as described above reduced the amount of data significantly. As examples of single particle mass spectra the averaged mass spectra for three single particle events are shown in Figure 10. The first spectrum (A) shows an internally mixed ammonium nitrate/ammonium sulfate particle with some organics and chloride. The diameter of this particle was $d_{v a}=405 \mathrm{~nm}$. The second spectrum (B) is from a "pure" ammonium sulfate particle of a size of $d_{v a}=315 \mathrm{~nm}$. The small green peaks in this spectrum, corresponding to organic material are similar to their noise levels. In the last plot (C), a spectrum from an ammonium nitrate particle, internally mixed with organic material and some chloride is shown. In this particle no sign of sulfate is found. The particle diameter of this particle was $d_{v a}=190 \mathrm{~nm}$. The most common single particle found during these measurements is of type (A): Internally mixed particles containing ammonium, nitrate, sulfate, and several peaks associated with organics.

Strong indication that the procedure to extract single particle events from the SP-TOF mode raw data generates real single particle mass spectra is given by Figure 5. In the top panel the total particle-related ion signal in the individual single particle mass spectra is plotted versus the particle diameter $d_{v a}$ together with a line proportional to $d_{v a}^{3}$. The markers are shaded according to the relative organics content in the particles, showing that the vast majority of particles contain a significant amount of inorganic species. The majority of particles $>150 \mathrm{~nm}$ diameter nearly follow the $d_{v a}^{3}$ line. The leveling off for particles $<150 \mathrm{~nm}$ reflects SP ion intensities biased by threshold rejection of smaller ion signals. About $97 \%$ of the extracted single particle mass spectra are clearly associated with individual particles, which is also reflected in the histogram of single particle events shown in the middle panel. The size distribution calculated by adding the total particle ion signal of each single particle event in the histogram for each particle diameter agrees well with the average total P-TOF mode size distribution for the days of SP-TOF mode measurements for particle diameters $d_{v a}>\sim 150 \mathrm{~nm}$. This also indicates that for particles of $d_{v a}>\sim 150 \mathrm{~nm}$ the detection in the SP-TOF mode works reliably. Smaller particles were detected with lower efficiency during the PMTACS-NY campaign. The increased noise of the size distribution calculated from the SPTOF mode data, compared to P-TOF mode data results from the significantly lower particle statistics $(\sim 3$ min of measurement, compared to 5 days in the P-TOF mode).

For each single particle event the concentration of the different species in the particle was calculated. By plotting the species concentrations against each other correlations between different species were detected within single particles.

For investigation of internal or external mixture of nitrate and sulfate in aerosol particles the nitrate and sulfate signal intensities in the SP events were plotted against each other in 

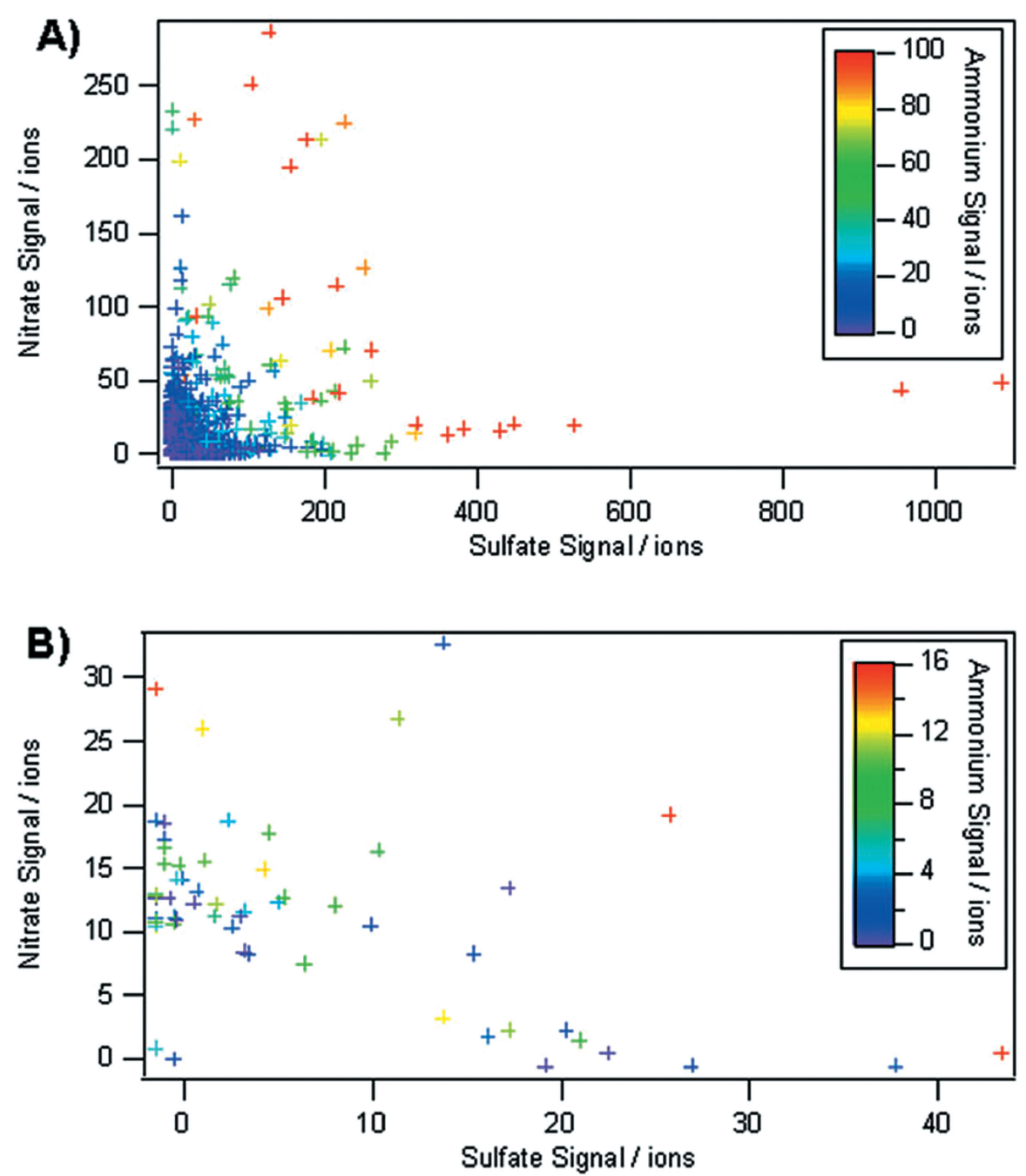

FIG. 11. Single particle nitrate signal plotted versus single particle sulfate signal for all single particle events (A), and the single particle events collected on January 27 (B). The markers are colored according to the ammonium signal intensity. For all single particle events two branches are found, showing partial external mixture of the species in the aerosol. The particles collected on January 27 are internally mixed.

Figure 11A. The markers of the scatter plot are colored according to the ammonium signal intensity of the single particle events. In this scatter plot two distinct branches were found outside a region close to the origin where the signal-to-noise ratio is very low: Particles with nitrate but little sulfate and particles with sulfate but little nitrate. In addition to these externally mixed particles there are particles with all ratios of mixture of nitrate and sulfate, showing up in between these extremes in the plot. As the coloring of the markers indicates ammonium is clearly associated with nitrate and sulfate: With increasing nitrate/sulfate signal the ammonium signal increases as well.

As shown in Figure 9 the averaged size distribution data suggest partial external mixture for all days where SP data were collected with the exception of January 27. In Figure 11B the same scatter plot of nitrate and sulfate signal in the single particle events is shown as in Figure 11A, but only events that are measured on January 27 are shown. On this day only single particle events with relatively low ion signal (see scale at axes) are found. Consequently the signal-to-noise is relatively low for all events. Also here single particles that contain sulfate but only low nitrate signal and vice versa are found, however the two branches that indicate externally mixed nitrate and sulfate are less distinct in this plot, compared to Figure 11A.

Even more clearly the differences of internal and external mixture of nitrate with the other species in the aerosol particles is found in the correlation plots of nitrate and organics signal in the single particle events, shown in Figure 12. Here the markers are colored according to the sulfate signal intensity in the particles. Looking at all single particle events (Figure 12A) two clearly separated branches are found for particles with nitrate but no organics and particles with organics, but no nitrate outside a region of low signal-to-noise close to the origin of 

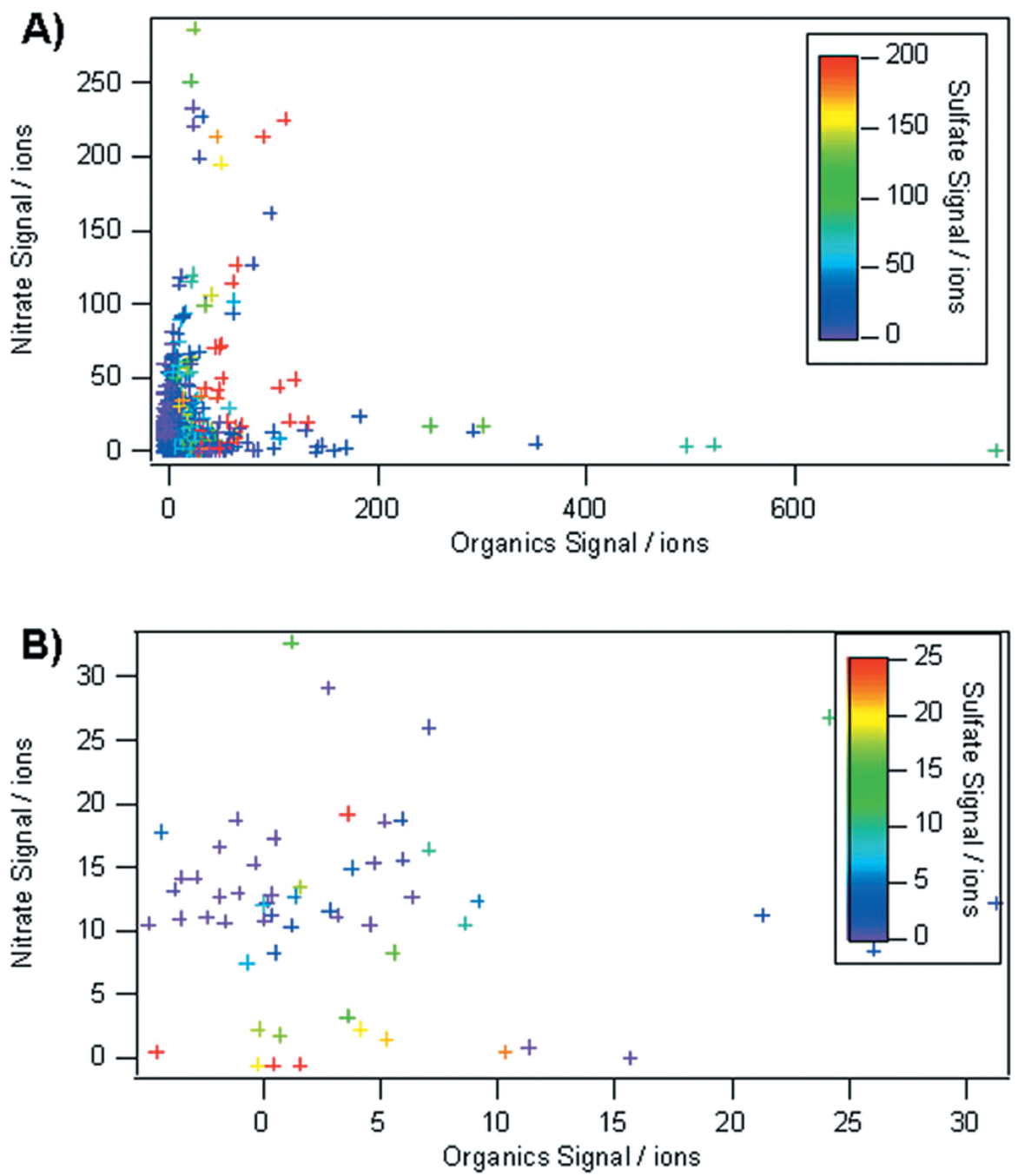

FIG. 12. Single particle nitrate signal plotted versus single particle organics signal for all single particle events (A), and the single particle events collected on January 27 (B). The markers are colored according to the sulfate signal intensity. For all single particle events two branches are found, showing external mixture of these species in the aerosol. The particles collected on January 27 are mainly internally mixed.

the plot. Only a few particles show internal mixture of both species with low organics concentrations. These particles typically also have high sulfate signal intensity (see color of the markers). For the other particles the sulfate signal intensity is low.

The correlation plot for the single particle events collected on January 27 looks very different (Figure 12B). Even though we again find only single particle events of relatively low intensity, we can find a difference with Figure 12A. In this plot the branch of nitrate-only particles is not found as in Figure 12A. Here we find a branch of markers from particles containing organics but no nitrate and we find a cloud of markers from particles that have all kinds of mixing of nitrate and organics. According to Figure 12B no nitrate particles externally mixed from organics are found for this day. Here the sulfate signal shows no trends within the mixture of nitrate and organics.
Here the single particle data confirm what was already suggested from the size distribution data: Internal mixture of nitrate, sulfate and organics on January 27 and partial external mixture of these species during the other days of single particle data collection.

\section{SUMMARY AND DISCUSSION}

The time-of-flight aerosol mass spectrometer (TOF-AMS) was deployed for the first time during the PMTACS-NY 2004 field campaign in New York City in January 2004. Data acquisition strategies and software were developed and tested. Here we report on the operation of the instrument, data acquisition and processing strategies, and first results from aerosol measurements during this campaign, as well as on intercomparison between the TOF-AMS data and data from a co-located Q-AMS. 
The TOF-AMS is based on the Aerodyne quadrupole-based Aerosol Mass Spectrometer (Q-AMS). It combines the Q-AMS particle collection, sizing and evaporation/ionization technology with a compact state-of-the-art orthogonal extraction time-offlight mass spectrometer and fast data acquisition electronics.

The TOF-AMS can measure in three different modes of operation. In the mass spectrum (MS) mode the ensemble average mass spectrum of the non-refractory ambient aerosol components is measured with high sensitivity. However no size information is obtained in this mode. In the particle time-of-flight (P-TOF) mode the aerosol particle beam is chopped with a mechanical chopper. In this mode species-resolved size distributions are determined from the particle flight time-dependent mass spectra, and a large number of chopper cycles are averaged. In the single-particle time-of-flight (SP-TOF) mode size dependent information on single particles are collected by acquiring data as in the P-TOF mode, but without averaging of spectra. Due to the enormous data production in this mode the data transfer into the PC was the bottleneck during this campaign, resulting in a data collection duty cycle of only $5 \%$. This duty cycle is expected to greatly increase in future versions of the data acquisition software by using on-board processing capabilities to compress the spectra on the data acquisition card before transfer to the PC memory. Scatter plots of species signal intensities in single particle events give direct information on internal or external mixture of certain species within the aerosol particles.

Due to the fact that the instrument was field tested during the PMTACS-NY 2004 experiment for the first time and that a first version of the data acquisition software was written just before and during the campaign, the data collected by the TOF-AMS consists of many short-term time period fragments and calibration routines were probably not completely mature, resulting in relatively large uncertainties in measured mass concentrations. Calibration procedures with significantly reduced uncertainties as well as corrections of the measured ion signals, for example for ion transmission efficiency through the mass spectrometer are currently being developed with the help of laboratory experiments and will be implemented in future versions of the TOF-AMS data acquisition and analysis software. However, the data clearly demonstrate the instrument's ability for sensitive aerosol composition and size distribution measurements as well as the possibility to directly determine the state and degree of mixing (internal or external) of species in individual particles with sufficient mass with high time resolution.

During this campaign a total of almost $180 \mathrm{~h}$ of aerosol mass concentration measurements, of more than $115 \mathrm{~h}$ of aerosol size distribution data, and single particle information on several time intervals on five days were collected. Comparison of these data with data measured with a co-located Q-AMS show strong correlation of the measured mass concentrations for the time interval where a valid mass concentration calibration was performed. Due to the ability of the TOF-MS, which produces a complete mass spectrum for every extraction and the fast extraction frequency of the TOF-MS the duty cycle of the TOF-AMS is sig- nificantly higher than the duty cycle of the Q-AMS. This is expected to result in lower detection limits for the TOF-AMS. Laboratory experiments in order to characterize the TOF-AMS, including determination of detection limits, are currently being performed and will be subject to a forthcoming publication (Hings et al. 2005). This effect can be observed especially in the species size distributions: They are much smoother and show more details compared to the Q-AMS size distributions, measured under identical conditions. Finally the single particle data measured during this campaign confirm expectations about internal or external mixture of particle components based on P-TOF mode data during certain time intervals of the campaign, and give additional information about the state of mixture that is not indicated by the P-TOF mode data.

To make the instrument more reliable and extract a maximum amount of information from the mass spectra three tasks have to be accomplished: Development of data acquisition software that allows a reliable operation of the instrument and full control of all its parts as well as the performance of accurate calibrations; development of data analysis software that extracts the maximum amount of information from the data produced by the instrument; and systematic characterization of the TOFAMS and all of its parts to allow most efficient operation of the instrument as well as correction for effects that could have an impact on measured properties like transmission efficiency dependence on ion mass. All three of these tasks are currently being worked on and will be part of future publications about the instrument and its applications.

\section{REFERENCES}

Alfarra, M. R., Coe, H., Allan, J. D., Bower, K. N., Boudries, H., Canagaratna, M. R., Jimenez, J. L., Jayne, J. T., Garforth, A., Li, S.-M., and Worsnop, D. R. (2004). Characterization of Urban and Rural Organic Particulate in the Lower Fraser Valley Using two Aerodyne Aerosol Mass Spectrometers, Atmospheric Environment 38: 5745-5758.

Allan, J. D., Jimenez, J. L., Coe, H., Bower, K. N., Williams, P. I., Jayne, J. T., and Worsnop, D. R. (2003). Quantitative Sampling Using an Aerodyne Aerosol Mass Spectrometer, Part 1: Techniques of Data Interpretation and Error Analysis, J. Geophysical Research-Atmospheres 108: 4090.

Allan, J. D., Bower, K. N., Coe, H., Boudries, H., Jayne, J. T., Canagaratna, M. R., Millet, D. M., Goldstein, A. H., Quinn, P. K., Weber, R. J., and Worsnop, D. R. (2004). Submicron aerosol composition at Trinidad Head, California, during ITCT 2K2: Its Relationship with Gas Phase Volatile Organic Carbon and Assessment of Instrument Performance, J. Geophysical Research 109:D23S24.

Allan, J. D., Delia, A. E., Coe, H., Bower, K. N., Alfarra, M. R., Jimenez, J. L., Middlebrook, Drewnick, A. M., F., Onasch, T. B., Canagaratna, M. R., Jayne, J. T., and Worsnop, D. R. (2004). A Generalised Method for the Extraction of Chemically Resolved Mass Spectra from Aerodyne Aerosol Mass Spectrometer Data, J. Aerosol Sci. 35:909-922.

Allen, J. O., Fergenson, D. P., Gard, E. E., Hughes, L. S., Morrical, B. D., Kleeman, M. J., Gross, D. S., Galli, M. E., Prather, K. A., and Cass, G. R. (2000). Particle Detection Efficiencies of Aerosol Time of Flight Mass Spectrometers Under Ambient Sampling Conditions, Environ. Sci. Technol. $34: 211$.

Andreae, M. O., and Crutzen, P. J. (1997). Atmospheric Aerosols: Biogeochemical Sources and Role in Atmospheric Chemistry, Science 276:10521058. 
Carson, P. G., Johnston, M. V., and Wexler, A. S. (1997a). Real-Time Monitoring of the Surface and Total Composition of Aerosol Particles, Aerosol Sci. Technol. 26:291-333.

Carson, P. G., Johnston, M. V., and Wexler, A. S. (1997b). Laser Desorption/Ionization of Ultrafine Aerosol Particles, Rapid Comm. Mass Spec. 11:993-996.

DeCarlo, P., Slowik, J. G., Worsnop, D. R., Davidovits, P., and Jimenez, J. L. (2004). Particle Morphology and Density Characterization by Combined Mobility and Aerodynamic Diameter Measurements. Part 1: Theory, Aerosol Sc. Technol. 38:1185-1205

Drewnick, F., Schwab, J. J., Hogrefe, O., Peters, S., Husain, L., Diamond, D., Weber, R., and Demerjian, K. L. (2003). Intercomparison and Evaluation of Four Semi-Continuous PM2.5 Sulfate Instruments, Atmos. Environ. 37:33353350.

Drewnick, F., Schwab, J. J., Jayne, J. T., Canagaratna, M., Worsnop, D. R., and Demerjian, K. L. (2004a). Measurement of Ambient Aerosol Composition During the PMTACS-NY 2001 Using an Aerosol Mass Spectrometer. Part I: Mass Concentrations, Aerosol Sci. Technol. 38(S1):92-103.

Drewnick, F., Jayne, J. T., Canagaratna, M., Worsnop, D. R., and Demerjian, K. L. (2004b). Measurement of Ambient Aerosol Composition During the PMTACS-NY 2001 Using an Aerosol Mass Spectrometer. Part II: Chemically Speciated Mass Distributions, Aerosol Sci. Technol. 38(S1):104-117.

Gard, E., Mayer, J. E., Morrical, R. D., Dienes, T., Fergensen, D. P., and Prather, K. A. (1997). Real-Time Analysis of Individual Atmospheric Aerosol Particles: Design and Performance of a Portable ATOFMS, Anal. Chem. 69:40834091.

Gross, D. S., Galli, M. E., Silva, P. J., and Prather, K. A. (2000). Relative Sensitivity Factors for Alkali Metal and Ammonium Cations in Single Particle Aerosol Time-of-Flight Mass Spectra, Anal. Chem. 72:416-422.

Heberlein, J., Postel, O., Girshick, S., McMurry, P., Gerberich, W., Iordanoglou, D., Di Fonzo, F., Neumann, D., Gidwani, A., Fan, M., and Tymiak, N. (2001). Thermal Plasma Deposition of Nanophase Hard Coatings, Surface \& Coatings Technology, 142:265-271.

Hings, S. S., Drewnick, F., Borrmann, S., DeCarlo, P., Jimenez, J. L., M. Gonin, Jayne, J. T., and Worsnop D.R. (2005). Characterization and Performance Evaluation of the Time-of-Flight Aerosol Mass Spectrometer (TOF-AMS), Aerosol Sci. Technol. (in preparation).

Hogrefe, O., Schwab, J. J., Drewnick, F., Lala, G. G., Peters, S., Demerjian, K. L., Rhoads, K., H. D. Felton, Rattigan, O. V., Husain, L., and Dutkiewicz, V. A. (2004). Semicontinuous PM2.5 Sulfate and Nitrate Measurements at an Urban and a Rural Location in New York: PMTACS-NY Summer 2001 and 2002 Campaigns, J. Air Waste Manag. Assoc. 54:1040-1060.

IPCC Report Climate Change. (2001). The Scientific Basis. Report of the Intergovernmental Panel on Climate Change. Cambridge University Press, New York.

Jayne, J. T., Leard, D. C., Zhang, X., Davidovits, P., Smith, K. A., Kolb, C. E., and Worsnop, D. R. (2000). Development of an Aerosol Mass Spectrometer for Size and Composition, Analysis of Submicron Particles, Aerosol Sci. Technol. 33:49-70.

Jimenez, J. L., Jayne, J. T., Shi, Q., Kolb, C. E., Worsnop, D. R., Yourshaw, I., Seinfeld, J. H., Flagan, R. C., Zhang, X., Smith, K. A., Morris, J., and Davidovits, P. (2003a). Ambient Aerosol Sampling with an Aerosol Mass Spectrometer, J. Geophys. Res._Atmospheres 108(D7):8425.

Jimenez, J. L., Bahreini, R., Cocker, D. R., Zhuang, H., Varutbangkul, V., Flagan, R. C., Seinfeld, J. H., O'Dowd, C., and Hoffmann, T. (2003b). New Particle Formation from Photooxidation of Diiodomethane (CH2I2), J. Geophys. Res-Atmospheres 108(D10):4090.

Johnston, M.V. (2000). Sampling and Analysis of Individual Particles by Aerosol Mass Spectrometry, J. Mass Spectrom. 35:585-595.

Kane, D. B., and Johnston, M. V. (2000). Size and Composition Biases on the Detection of Individual Ultrafine Particles by Aerosol Mass Spectrometry, Environ. Sci. Technol. 34:4887-4893.

Liu, P., Ziemann, P. J., Kittelson, D. B., McMurry, P. H. (1995a). Generating Particle Beams of Controlled Dimensions and Divergence: I. Theory of Par- ticle Motion in Aerodynamic Lenses and Nozzle Expansions, Aerosol Sci. Technol. 22:293-313.

Liu, P., Ziemann, P. J., Kittelson, D. B., and McMurry, P. H. (1995b). Generating Particle Beams of Controlled Dimensions and Divergence: II. Experimental Evaluation of Particle Motion in Aerodynamic Lenses and Nozzle Expansion, Aerosol Sci. Technol. 22:314-324.

Mahadevan, R., Lee, D., H. Sakurai, and Zachariah, M. R. (2002). Measurement of Condensed Phase Reaction Kinetics in the Aerosol Phase Using SingleParticle Mass-Spectrometry, J. Physical Chem. A. 106:11083.

McKeown, P. J., Johnston, M. V., and Murphy, D. M. (1991). On-Line Single Particle Analysis by Laser Desorption Mass Spectrometry, Anal. Chem. 63:2069-2073.

McMurry, P. A. (2000). A Review of Atmospheric Aerosol Measurements, Atmos. Environ. 34:1959-1999.

Morrical, B. D., Fergenson, D. P., and Prather, K. A. (1998). Coupling Two-Step Laser Desorption/Ionization with Aerosol Time-of-Flight Mass Spectrometry for the Analysis of Individual Organic Particles, J. Am. Soc. Mass Spectrom. 9:1068-1073.

Murphy, D.M., and Thomson, D. S. (1997). Chemical Composition of Single Aerosol Particles ad Idaho Hill: Positive Ion Measurements, J. Geophys. Res. 102:6341-6368.

Pope, C. A., Burnett, R. T., Thun, M. J., Calle, E. E., Krewski, D., Ito, K., and Thurston, G. D. (2002). Lung Cancer, Cardiopulmonary Mortality, and Long-Term Exposure to Fine Particulate Air Pollution, J. Am. Med. Assoc. 287:1132-1141.

Reents, W. D., and Ge, Z. (2000). Simultaneaous Elemental Composition and Size Distributions of Submicron Particles in Real Time Using Laser Atomization/Ionization Mass Spectrometry, Aerosol Sci. Technol. 33:122-134.

Reilly, P. T. A., Lazar, A. C., Gieray, R. A., Whitten, W. B., and Ramsey, J. M. (2000). The Elucidation of Charge-Transfer-Induced Matrix Effects in Environmental Aerosols Via Real-Time Aerosol Mass Spectral Analysis of Individual Airborne Particles, Aerosol Sci. Technol. 33:135-152.

Samet, J. M., Dominici, F., Curriero, F. C., Coursac, I., and Zeger, S. L. (2000). Fine Particulate Air Pollution and Mortality in 20 U. S. Cities, New Engl. J. Med. 343:1742-1749.

Schneider, J., Borrmann, S., Wollny, A. G., Bläsner, M., Mihalopoulos, N., Oikonomou, K., Sciare, J., Teller, A., Levin, Z., and Worsnop, D. R. (2004). Online Mass Spectrometric Aerosol Measurements During the MINOS Campaign (Crete, August 2001), Atmos. Chem. Phys. 4:65-80.

Seinfeld, J. H., and Pandis, S. N. (1999). Atmos. Chem. Phys. John Wiley and Sons, New York.

Smith, J. N., Moore, K. F., McMurry, P. H., and Eisele, F. L. (2004). Atmospheric Measurements of Sub-20 nm Diameter Particle Chemical Composition by Thermal Desorption Chemical Ionization Mass Spectrometry, Aerosol Sci. Technol. 38:100-110.

Steiner, W. E., Clowers, B. H., Fuhrer, K., Gonin, M., Matz, L. M., Siems, W. F., Schultz, A. J., and Hill, Jr., H. H. (2001). Electrospray Ionization with Ambient Pressure ion Mobility Separation and Mass Analysis by Orthogonal Timeof-Flight Mass Spectrometry, Rapid Communications in Mass Spectrometry 15:2221-2226.

Tobias, H. J., and Ziemann, P. J. (1999). Compound Identification in Organic Aerosols Using Temperature-Programmed Thermal Desorption Particle Beam Mass Spectrometry, Anal. Chem. 71:3428-3435.

Wang, S., Chen, H., and Johnston, M. (2004). Elemental Compositions of Individual Particles with a Laser-Induced Plasma Source for Mass Spectrometry. 23rd Annual American Association for Aerosol Research Conference, Atlanta, GA, 2004.

Warneck, P. (1999). Chemistry of the Natural Atmosphere. Academic Press, New York.

Watson, John, G. (2002). Visibility: Science and Regulation, J. Air and Waste Manag. Assoc. 52(6):628-713.

Weimer, S., Drewnick, F., Hogrefe, O., Schwab, J. J., Rhoads, K., Orsini, D., Demerjian, K. L., Worsnop, D. R., Zhang, Q., Jimenez, J. L., and Felton, D. (2005). Measurement of Ambient Aerosol Composition Using an Aerodyne 
Aerosol Mass Spectrometer in New York City: Winter 2004 Intensive Study, Environ. Sci. Technol. (in preparation).

Wichmann, H.-E., Spix, C., Tuch, T., G. Wölke, Peters, A., Heinrich, J., Kreyling, W. G., and Heyder, J. (2000). Daily Mortality and Fine and Ultrafine Particles in Erfurt, Germany. Part I: Role of Particle Number and Particle Mass. Health Effects Institute Research Report 98.

Zelenyuk, A., Cabalo, J., Baer, T., and Miller, R. E. (1999). Mass Spectrometry of Liquid Aniline Aerosol Particles by IR/UV Laser Irradiation, Anal. Chem. 71:1802-1808.

Zhang, Q., Canagaratna, M. R., Jayne, J. T., Worsnop, D. R., and Jimenez, J.-L. (2005). Time and Size-Resolved Chemical Composition of Submicron Particles in Pittsburg-Implications for Aerosol Sources and Processes, Journal of Geophysical Research-Atmospheres 110 (DO7SO9), doi: 10.1029/2004JD004649.
Zhang, Q., Stanier, C. O., Canagaratna, M. C., Jayne, J. T., Worsnop, D. R., Pandis, S. N., and Jimenez, J. L. (2004a). Insights into the Chemistry of Nucleation Bursts and New Particle Growth Events in Pittsburgh Based on Aerosol Mass Spectrometry, Environ. Sci. Technol. 38:47974809.

Zhang, Q., Alfarra, M. R., Worsnop, D. R., Allan, J. D., Coe, H., Canagaratna, M. R., and Jimenez, J. L. (2004b). Deconvolution and Quantification of Primary and Oxygenated Organic Aerosols Based on Aerosol Mass Spectrometry. Part 1: Development and Validation of the Method. Environ. Sci. Technol. (submitted).

Zhang, X., Smith, K. A., Worsnop, D. R., Jimenez, J. L., Jayne, J. T., and Kolb, C. E. (2002). A Numerical Characterization of Particle Beam Collimation by an Aerodynamic Lens-Nozzle System: Part I. An Individual Lens or Nozzle, Aerosol Sci. Technol. 36:617-631. 